\title{
Theoretical analysis and parametric investigation of an innovative helical air gap membrane desalination system
}

\author{
Vandita T. Shahu ${ }^{1}$ (D) . Shashikant B. Thombre ${ }^{1}$
}

Received: 6 September 2021 / Accepted: 22 December 2021 / Published online: 28 January 2022

(c) The Author(s) 2022

\begin{abstract}
A helical air gap membrane desalination (HAGMD) system is designed in the present study. The condenser is designed as a cylindrical shape with helical fins machined on the outer surface of a hollow copper condenser. A detailed theoretical model, studying heat and mass transfer in the HAGMD module, was developed. The theoretical model for a cylindrical system with fins is developed for the first time and is unique in the MD literature. Experimentation was carried out to examine the behavior of the HAGMD module under diverse design and operating conditions. The effect of cold flow rate, feed flow rate, feed temperature, the height of fins, the number of fins, and the length of the module is determined on the performance of the HAGMD system. Permeate flux and gained output ratio (GOR) were considered as the performance indicators of the system. Results showed that permeate flux increases with cold flow rate, feed temperature, feed flow rate, as well as number of fins, while the increase in height of fins negatively affects the flux. Theoretical model and experimental results are found to be in excellent agreement with only $6.7 \%$ of error which shows that the present theoretical model is excellent to predict the performance of any HAGMD system. For similar design parameters, the average flux increased by $135 \%$ for the finned HAGMD module, with 35 fins over the one with that only for $1 \mathrm{fin}$. Maximum experimental distillate flux is found to be $20 \mathrm{~kg} / \mathrm{m}^{2} \mathrm{hr}$, and GOR is found to be 0.75 .
\end{abstract}

Keywords Helical air gap membrane distillation · Energy efficiency · Flux · Fins · Theoretical modeling · GOR

\section{List of symbols}

$A_{m} \quad$ Membrane area $\left(\mathrm{m}^{2}\right)$

$B_{w} \quad$ Overall mass transfer coefficient $\left(\mathrm{kg} / \mathrm{m}^{2} \mathrm{hPa}\right)$

$C_{p} \quad$ Specific heat of the fluid $(\mathrm{J} / \mathrm{kgK})$

$D_{h} \quad$ Characteristic dimension, hydraulic diameter (m)

$g \quad$ Acceleration due to gravity $\left(\mathrm{m} / \mathrm{s}^{2}\right)$

$h_{d} \quad$ Heat transfer coefficient of $\left(\mathrm{W} / \mathrm{m}^{2} \mathrm{~K}\right)$ condensate

$h_{f g} \quad$ Enthalpy of vaporization $(\mathrm{J} / \mathrm{kgK})$

$k$ Thermal conductivity of the fluid (W/mK)

$k_{\text {metal }}$ Thermal conductivity of the condenser material $(\mathrm{W} / \mathrm{mK})$

$k_{\text {film }} \quad$ Thermal conductivity of the condensate film (W/ $\mathrm{mK})$

$k_{p} \quad$ Thermal conductivity of permeate $\left(\mathrm{W} / \mathrm{m}^{2}\right)$

$k_{g} \quad$ Thermal conductivity of the air in the gap $(\mathrm{W} / \mathrm{mK})$

$k_{m} \quad$ Thermal conductivity of the membrane (W/mk) $k_{\text {sup }} \quad$ Thermal conductivity of the support net material (W/mK)

$L_{b} \quad$ Length of the condensate film (m)

$L_{g} \quad$ Vertical length of the section between two fins (m)

$L_{d} \quad$ Air gap width/height of fin

$L_{g} \quad$ Vertical length of the section between two fins (m)

$L \quad$ Vertical length of the module (m)

$n \quad$ Number of finned sections

$\mathrm{Nu} \quad$ Nusselt number

$P_{v} \quad$ Vapor pressure (bar)

Pr Prandtl number

Re Reynolds number

$T \quad$ Temperature (K)

$t \quad$ Total time for permeate collection (hr)

$V \quad$ Velocity of fluid (m/sec)

$W \quad$ Weight of the permeate $(\mathrm{kg})$

Vandita T. Shahu

Vandita.tha@gmail.com

1 Department of Mechanical Engineering, Visvesvaraya

National Institute of Technology, Nagpur 440010, India 


\section{Introduction}

Out of all, the most important element for life is water. About $71 \%$ of the earth's surface is covered with water, and still, we are facing water scarcity just because of mismanaged use of water resources. According to the WHO/UNICEF joint monitoring program for Water Supply and Sanitation, at least 1.8 billion people worldwide are estimated to drink water that is fecally contaminated. By 2025 , total water demand increases from $680 \mathrm{Bm} 3$ in the year 2000 to 833 Bm3 by 2025 and to $900 \mathrm{Bm} 3$ by the year 2050 (Hanemaaijer et al. 2006). Therefore, it is always advisable to use the water resources efficiently and wisely to render a better future for water availability. Membrane distillation (MD) is a fast-emerging technology to solve many potable and clean water problems. MD is a separation technology that uses difference of temperatures on both sides of the membrane to get the freshwater from the saline or brackish solution. MD can utilize even low-temperature gradients, and therefore, it is highly recommended to be used in conjunction with renewable energy resources like solar or geothermal energy sources or with low-grade waste heat wherever available to get fresh water with lower overall cost. Several studies have stated the advantages of MD over other thermal-based desalination technologies, like multi-stage flash and multi-effect distillation that should be considered while searching for pure water solutions. Some of the advantages of MD apart from utilizing low-grade heat are lower operating costs, no need for high pretreatment, ability to recover heat from brine (Hanemaaijer et al. 2006), ability to make the setup from cheaper materials, ability to recover costly solution without diluting, no membrane deterioration due to the intermittent operation (Elhenawy et al. 2020). Air gap membrane distillation (AGMD) methods are favorable over other MD configurations due to their ability to be used even with very high salinity solutions (Swaminathan et al. 2018), allow internal heat recovery (Khayet and Matsuura 2011a), and higher thermal efficiency (Khayet and Cojocaru 2012). AGMD has been used for different kinds of feeds to be separated and purified due to its property of providing undiluted permeate, for example; some of the feed considered, other than saline feed, are ethanol-water mixture (Banat and Simandl 1999), aqueous solutions of alcohol (ethanol, methanol, or isopropanol) (Garciá -Payo et al. 2000), sucrose aqueous solutions (Izquierdo-Gil et al. 1999), milk concentration (Moejes et al. 2020), humidification of damaged paintings (Szczerbińska et al. 2017), wastewater concentration (Schwantes et al. 2019). Alkhudhiri et al. (2017) presented a detailed AGMD study to analyze the effect of different salts of $\mathrm{NaCl}, \mathrm{MgCl}_{2}, \mathrm{Na}_{2} \mathrm{CO}_{3}$, and $\mathrm{Na}_{2} \mathrm{SO}_{4}$ with a high concentration on the permeate flux production and rejection factor. They also used three membranes with different pore sizes to check the influence of pore size on the performance. They stated that with higher salt concentration, permeate flux and rejection factor decrease, while energy consumption increases due to increased boiling point and decreased liquid entry pressure (Alkhudhiri and Hilal 2017). Usually, AGMD has been used with conventional plate and frame (Khalifa and Lawal 2016; Charfi et al. 2010; Khayet and Matsuura 2011b) and hollow fiber (Cabassud and Wirth 2003; Cheng et al. 2009; Guijt et al. 2005a, b) designs, but nowadays number of different configurations are appearing in the literature that explore new design possibilities to study AGMD systems (Shahu and Thombre 2019a). Aryapratama et al. (2016) designed a hollow fiber module with multiple cooling channel network made up of stainless steel. They considered the effect of inner and outer module channels, feed temperature, feed flow rate, membrane packing position, membrane surface area to condensation surface area ratio, and comparison through DCMD. The maximum flux in their system was $12.5 \mathrm{~kg} / \mathrm{m}^{2} \mathrm{~h}$, and thermal efficiency was as high as $81.7 \%$. Summers et.al presented a novel idea of direct solar heating of membrane to result in an increased thermal efficiency (Summers and Lienhard 2013). They also included reduced pressure for lower diffusion resistance in the air gap. The maximum gained output ratio (GOR) they achieved was 0.35 for 0.4 ATM pressure. Cheng et al. (2011) introduced vertical grooves on surface of the condenser and developed a finned tubular AGMD system. They tested the configuration for small and large modules. A very high flux of $50 \mathrm{~kg} / \mathrm{m}^{2} \mathrm{~h}$ resulted with 11 grooves. For large modules with 10 such tubes, they incorporated a solar heat-driven system and the average permeate flux developed was $6 \mathrm{~kg} /$ $\mathrm{m}^{2} \mathrm{~h}$. Bahar et.al developed a channeled coolant plate to increase the heat transfer during condensation to result in increased flux (Bahar et al. 2015). They showed the variation of flux with circular, rectangular, and triangular-shaped fins and mentioned that the best suitable shape is circular as it does not entrap condensate, although the maximum flux obtained in their study was $23.63 \mathrm{~kg} / \mathrm{m}^{2} \mathrm{~h}$ for rectangular fins. Elhenawy et al. (2020) developed an AGMD system with novel spacer and corrugated feed channels. They demonstrated that the maximum flux enhancement of permeate flux was $50 \%$ for the corrugated channel and $40 \%$ for the spacer feed channel, while the respective figures for GOR are $20 \%$ and $10 \%$. It was also shown that the temperature polarization constant could reach nearly unity for corrugated feed spacers. Shahu et al. (2019b) demonstrated design flexibility for MD modules similar to the design of shell and tube heat exchangers. They developed a cylindrical AGMD module with a hollow copper condenser. The maximum flux in their study could reach $3.6 \mathrm{~kg} / \mathrm{m}^{2} \mathrm{~h}$. A double-pipe AGMD module was designed with PVDF hollow fiber membranes and capillary copper tube for heat exchange by Liu et al. (2016). They introduced a term as equivalent distillation 
flux by combining the effect of permeate flux and GOR, which can enable one to evaluate the comprehensive performance of AGMD systems. The maximum flux in their system reported was $11.4 \mathrm{~kg} / \mathrm{m}^{2} \mathrm{~h}$, and GOR was 6.6. There were a number of modifications in the basic AGMD module by changing the air gap conditions such as filling the air gap with insulating materials to result in a material gap MD module (Francis et al. 2013), filling the air gap with permeate to result in a permeate gap or water gap configuration (Gao et al. 2019; Swaminathan et al. 2016a; Amali et al. 2004; Im et al. 2018a, b), filling the gap with conductive metal support spacer along with permeate to increase gap conductivity and result in a conductive gap AGMD module (Swaminathan et al. 2016a).

From the literature, it is found that no theoretical analysis has been performed for cylindrical MD modules. Heat and mass transfer behavior is not studied for such modules, neither the idea is provided for the same. In the present study, a design modification in the conventional AGMD modules is performed in a way to result in an improved desalination system. The achievements are in the terms of increased permeate flux and GOR. The design changes are done in the form of helical fins machined on the outer surface of a cylindrical condenser made of copper. The system is termed as helical air gap membrane distillation (HAGMD) module used for desalination purpose in this study. The system results in increased thermal conductivity of the air gap due to the presence of helical conductive copper fins. Heat transfer to the cold fluid from the fins through the conductive copper condenser is also improved, which ultimately results in increased cold side heat transfer coefficient and improved thermal efficiency and flux. To determine the behavioral trend of the HAGMD system the effect of not only the operating parameters were studied, but also major design parameters were considered, so that the effect of design can be analyzed. The study may also serve as a guide for suggesting the system performance in case of scale-up modules. The operating parameters selected were feed and cold flow rate, and feed temperature. The design parameters were selected as the number of fins, air gap width that in turn is equal to the height of fins, and length of the module. A detailed theoretical model was developed for analyzing the heat and mass transfer behavior of the cylindrical HAGMD system. The model considers the effect of all the design, as well as operating parameters mentioned above. The theoretical model was firstly made for a rectangular module and validated with the literature (Khalifa and Lawal 2015). Then it was converted to a cylindrical model and the same was validated with a cylindrical AGMD system without the fins. The description of the CAGMD system can be found in the past study (Shahu and Thombre 2019b). Then the model was developed with the helical fins, and the same was validated with the experiments in the present study. This renders the model to be completely validated with the experiments as well as with the literature. An excellent agreement of 93.3 $\%$ was observed between the model and experiments, which shows that the present theoretical model can be used for studying the performance of the HAGMD system.

In the next section, the HAGMD system will be briefly described which will help to understand the theoretical model, and then the principle and theoretical analysis will be presented. After the theoretical model, the experimental setup and the performance methodology will be explained. Then the results will be discussed to explain the system performance, and the strategies will be suggested to result in an improved system performance to result in a higher permeate flux and GOR.

\section{Materials and methods}

\section{Description of helical air gap membrane desalination module}

A helical air gap membrane distillation module is a cylindrical AGMD module with helical fins machined on the outer surface of a conductive copper tube (Shahu and Thombre 2021). The complete details of the components and the assembly are shown in a three-dimensional Fig. 1 that is self-explanatory. The condenser tube is hollow that allows the flow of cold water from within to keep the condenser surface cooled. A polytetrafluoroethylene (PTFE) membrane of flat sheet type is used as the separating member that filters out the freshwater from the saline feed. The PTFE membrane is enveloped over the condenser and is sticked at the vertical ends so that to cover the finned condenser and to form a cylindrical-shaped membrane. This condenser tube assembled with the membrane over it, undergoes a hollow shell and is fixed on its top and bottom ends to resemble a shell and tube configuration, depicted in part (a) of Fig. 1. Part (a) shows how the system will look like if the outer shell is transparent. But in the present case, the outer shell is made up of stainless steel and therefore the system looks like that in part (b) of Fig. 1. The shell holds the entry and exit for the hot feed. The feed flows over the membrane and leaves from the shell top. The continuous helical fins also support the membrane. The permeate leaves from the condenser bottom at the end of the helical fins as shown in the figure.

\section{Principle of HAGMD system}

The permeate separation principle for the present system is similar as reported in the literature (Goh et al. 2016; Xie et al. 2016; Suárez et al. 2015; Duong et al. 2016). The driving force for the separation is the transmembrane temperature difference that is developed due to different temperature regions on two sides 


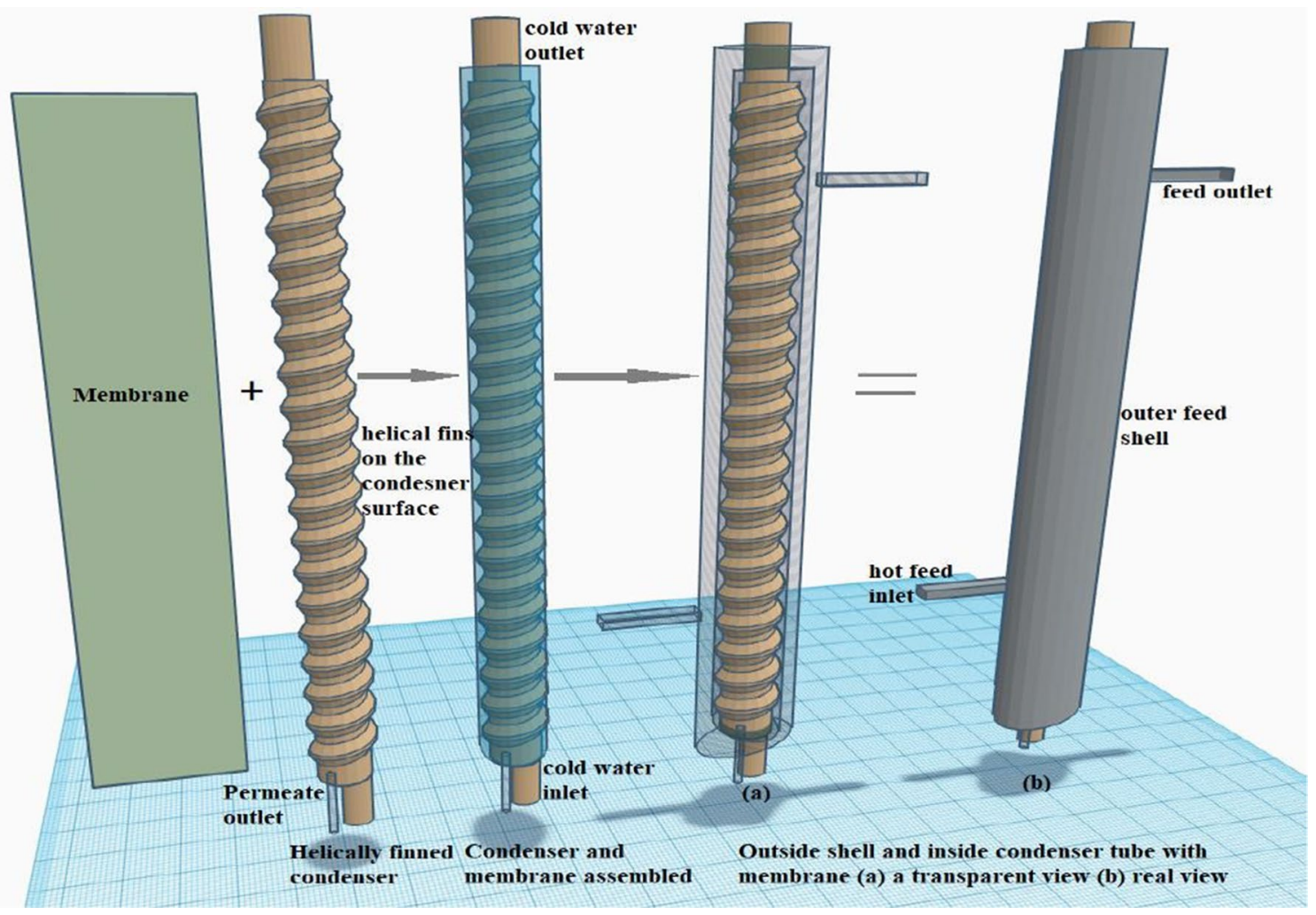

Fig. 1 Components and assembly details of HAGMD module

of the membrane. The feed flows in the outer shell at a higher temperature. After the membrane, an air gap followed by the cold condenser tube containing fins is present. This difference in the temperature across the membrane results in different vapor pressure, and the feed vaporizes on the feed-membrane interface to balance this difference. The vapors formed pass through the hydrophobic PTFE membrane and get condensed on the fins as well as on the condenser tube wall. The condensate formed travels over the helical finned passage to the bottom starting from the top and leaves through the exit provided at the bottom. The flowing condensate may also develop a centrifugal inertial suction force as it flows in a helical manner, sweeping the condensate diffusing through the membrane surface (Video 1, Annexure 1), and this way the vaporization may be accelerated at the feed-membrane interface. However, this effect may be minor but may help in the vaporization and therefore in increased the permeate production (Shahu and Thombre 2021).

The overall length of the condenser tube is divided into a number of smaller lengths due to the presence of fins on its outer surface. This results in a reduction of the overall length of the condensate films on each finned section. From the film heat transfer coefficient theory derived by Nusselt (Eq. 1), it is clear that reduction in the film height increases the heat transfer coefficient that helps in better heat transfer through the condensate film to the condenser surface (Kumar et al. 2008). This increases the condensation heat transfer. $h_{d}=0.943\left(\frac{g \cdot \rho_{d}^{2} h_{f g} k_{p}^{3}}{L_{b} \mu_{d}\left(T_{2}-T_{4}\right)}\right)^{0.25}$

Further, the provision of fins results in increased overall surface area for condensation and helps in increased permeate production as well as heat recovery to the cold fluid. The fins and the condenser tube are made up of copper as the thermal conductivity of this metal is very high that will facilitate the heat transfer through them. The copper was selected as the fin material because the inclusion of copper in the potable water helps in adding important nutrients and makes it more beneficial for the health (Shahu and Thombre 2021).

\section{Theoretical modeling of HAGMD}

The principle of heat and mass transfer analysis for the HAGMD system is presented and modeled mathematically in this section. Figure 2 shows the top and front sectional view of the HAGMD module. The different lengths and the radiuses from the axis of symmetry up to the relevant points are also shown in the same figure. The respective temperatures occurring at different points at each radial distances are shown at the bottom of the figure. Only one section between two consecutive fins is shown here for the simplicity of understanding. 

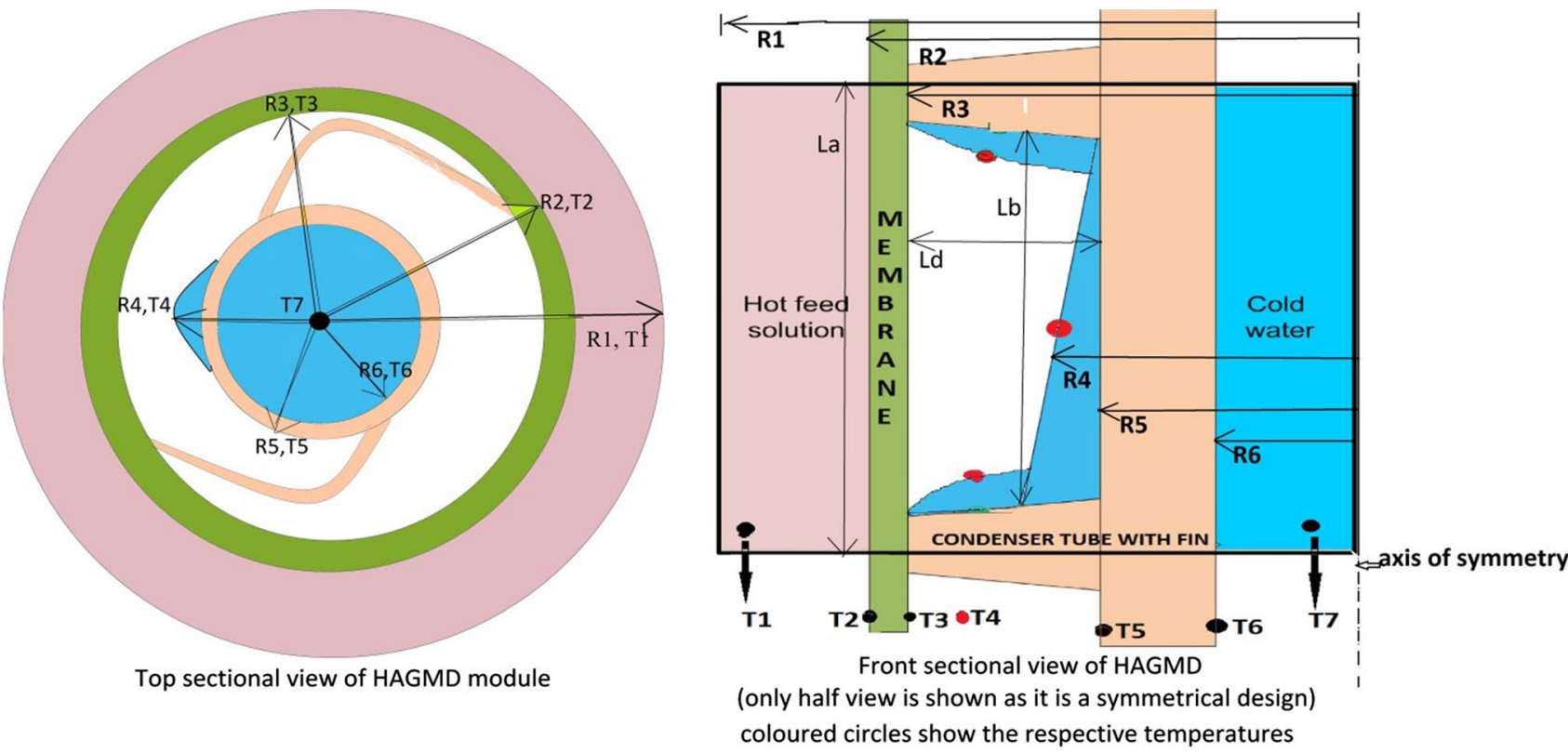

Fig. 2 Top and sectional view of one finned section

Some of the assumptions that are specific for modeling of the HAGMD module are:

1. The system analysis is performed at a steady state

2. The air is assumed to be stationary in the air gap

3. The heat loss to the surrounding is neglected

4. The axial changes in the temperature are neglected while calculating the radial temperature distribution

5. There is always some air present in the air gap between the fins, and the gap is not completely filled with the permeate.

\section{Heat transfer}

The heat transfer analysis and concerned equations for each section are presented sequentially for the cylindrical HAGMD system. The thermal network for the heat transfer is shown in Fig. 3. It is to be mentioned that due to the phenomenon of temperature polarization that emphasizes the effect of boundary layer resistance over the heat transfer resistance (Hanemaaijer et al. 2006) the bulk feed temperature and the temperature at the membrane-feed interface are different and are, respectively, indicated by the temperatures $T_{1}$ and $T_{2}$; similarly, the temperatures at the coolant side at condensate surface and the bulk cold fluid are different and are indicated by $T_{3}$ and $T_{4}$. Therefore, the present model takes care of the temperature polarization phenomenon within the HAGMD module.

Hot feed section Heat is transferred from hot feed solution to the membrane by convection:

$Q_{1}=h_{f} 2 \pi r_{2} L\left(T_{1}-T_{2}\right)$

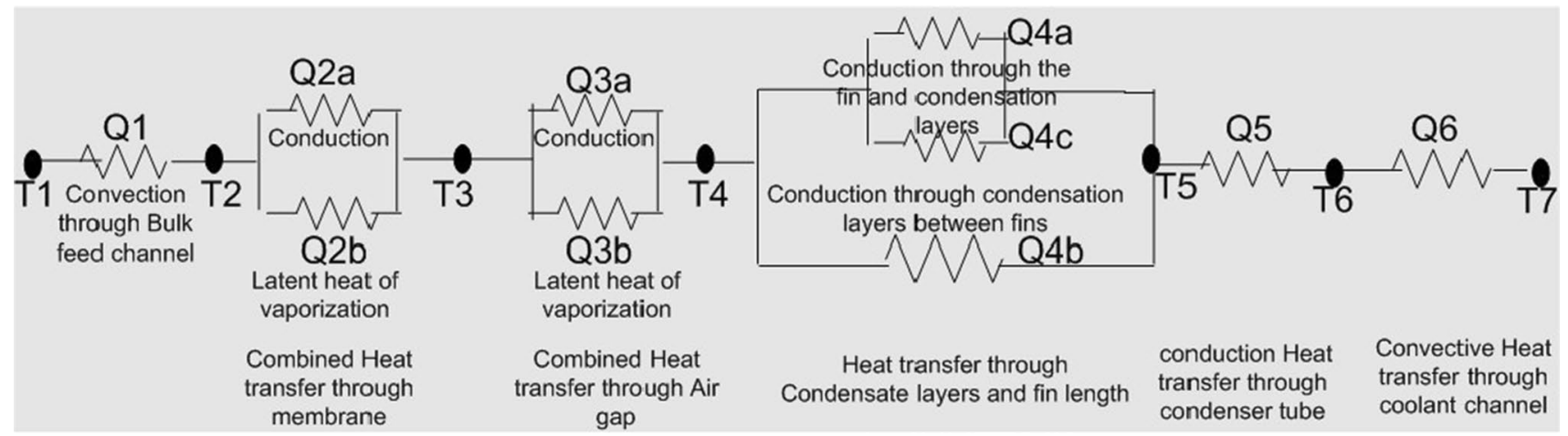

Fig. 3 Heat flow circuit in HAGMD 
So : $T_{1}-T_{2}=Q_{1} / h_{f} 2 \pi r_{2} L$

here $Q_{1}$ is the heat transferred through the feed solution to the membrane (W), $r_{2}$ is the radius from the core of the module to the feed section (m), $L$ is the length of the module (m), $T_{1}$ is the average feed temperature $(\mathrm{K})$, and $T_{2}$ is the feed side membrane surface temperature $(\mathrm{K})$.

Membrane The heat is transferred by two combined modes through the membrane. First as the conduction through the membrane material and other in the form of latent heat of vaporization carried by the vapor mass diffusing through the membrane.

$Q_{2}=Q_{2 a}+Q_{2 b}$

Therefore $Q_{2}=\frac{2 \pi k_{m} L\left(T_{2}-T_{3}\right)}{\log \left(\frac{r_{2}}{r_{3}}\right)}+J h_{f g}$

where $Q_{2 a}=\frac{2 \pi k_{m} L\left(T_{2}-T_{3}\right)}{\log \left(\frac{r_{2}}{r_{3}}\right)}$ and $Q_{2 b}=J h_{f g}$ = latent heat of vaporization associated with the flux.where $Q_{2}$ is the heat transferred across the membrane (W), $J$ is the total permeate flux $\left(\mathrm{kg} / \mathrm{m}^{2} \mathrm{sec}\right), r_{2}$ and $r_{3}$ are the outer and inner radius (m), $T_{3}$ is the average air gap side membrane surface temperature (K).

Hence $T_{2}-T_{3}=\left(Q_{2}-J \cdot h_{f g}\right) \cdot \frac{\log \left(\frac{r_{2}}{r_{3}}\right)}{2 \pi k_{m} L}$

Air gap region The heat is transferred by two combined modes through the air gap. First as the conduction through the air gap and other in the form of latent heat of vaporization carried by the vapors traveling through the air gap up to the condensate layer and the fins.

$Q_{3}=Q_{3 a}+Q_{3 b}$

$Q_{3}=\frac{2 \pi n k_{g} L_{g}\left(T_{3}-T_{4}\right)}{\log \left(\frac{r_{3}}{r_{4}}\right)}+J h_{f g}$

where $Q_{3 a}=\frac{2 \pi n k_{g} L_{g}\left(T_{3}-T_{4}\right)}{\log \left(\frac{r_{3}}{r_{4}}\right)}$ is the heat transferred by conduction through the air gap, and $Q_{3 b}=J h_{f g}$ shows latent heat of vaporization linked with the vapor mass transfer.where $Q_{3}$ is the heat transferred through the air gap till the condensate layer (W), $r_{3}$ and $r_{4}$ are the radius ( $\left.\mathrm{m}\right), L_{g}$ is the vertical length of the section between two fins (m), $T_{4}$ is the condensate layer surface temperature (K), and $n$ is the number of finned sections or fins.here $L_{g}=L_{a}-2 w$, and pitch of the helix $L_{a}=L / n$.

Now $T_{3}-T_{4}=\left(Q_{3}-J \cdot h_{f g}\right) \cdot \frac{\log \left(\frac{r_{3}}{r_{4}}\right)}{2 \pi n k_{g} L_{g}}$

Condensate region The vapor encounters the condenser wall and fins after the air gap and get condensed over it. The heat is transferred at three condensate layers in this region. Two condensate layers are formed each at the top and the bottom fins and one between the fins as shown in Fig. 2. The efficiency of the fins is determined for the circular fins, and it is found to be more than $95 \%$, and therefore, the whole fin is considered to be the fin with insulated tips at the average base temperature, i.e., at $T_{5}$ for the calculations (Incropera 2006). For one section the heat transfer is calculated as: $Q_{4}=Q_{4 a}+Q_{4 b}+Q_{4 c}$. where $Q_{4 a}, Q_{4 c}$ are the total heat transferred through the fins. They are assumed to be equal and therefore ultimately $Q_{4 a}=Q_{4 c}$

$Q_{4 a}=\sqrt{h_{d_{1}} \cdot P_{\text {fin }} \cdot K_{\text {fin }} \cdot A_{\text {cs.fin }}} \cdot \tanh (m b) \cdot\left(T_{4}-T_{5}\right) \eta_{\text {fin }} \cdot n$

here:

Perimeter of fin, $P_{f i n}=2 . \pi .\left(r_{3}-r_{5}\right)$.

Cross-sectional area of fin $A_{\text {cs.fin }}=2 . \pi \cdot\left(r_{2 c}^{2}-r_{5}^{2}\right)$ and, $r_{2 C}=r_{3}+w$

$h_{d_{1}}=c_{1} \cdot \frac{4}{3} \cdot \frac{k_{\text {film }}}{\delta_{\text {film }}}$

here $c_{1}$ is the McAdam's correction factor for the steam condensing on the vertical cylinders, and its value is 1.2 (Kumar et al. 2008).

$Q_{4 b}$ is the total heat transferred by the conduction through the vertical condensate layer between the fins.

$Q_{4 b}=\frac{2 \pi k_{\mathrm{film}} L_{b} n\left(T_{4}-T_{5}\right)}{\log \left(\frac{r_{4}}{r_{5}}\right)}$

$$
Q_{4}=2 \sqrt{h_{d_{1}} \cdot P_{f i n} \cdot K_{f i n} \cdot A_{c s . f i n}} \cdot \tanh (m b) .
$$

Therefore: $\left(T_{4}-T_{5}\right) \eta_{\text {fin }} \cdot n+\frac{2 \pi k_{f i l m} L_{b} n\left(T_{4}-T_{5}\right)}{\log \left(\frac{r_{4}}{r_{5}}\right)}$

That converts in to:

$T_{4}-T_{5}=Q_{4} /\left\{\left(\sqrt{h_{d_{1}} \cdot P_{\text {fin }} \cdot K_{\text {fin }} \cdot A_{\text {cs.fin }} \cdot} \tanh (m b) \cdot\left(T_{4}-T_{5}\right) \eta_{\text {fin }} \cdot n\right)+\frac{2 \pi k_{\text {film }} L_{b} n\left(T_{4}-T_{5}\right)}{\log \left(\frac{r_{4}}{r_{5}}\right)}\right\}$ 
Condenser region The heat is transferred through the copper condenser tube wall by conduction.

$Q_{5}=\frac{2 \pi k_{\text {metal }} L \cdot\left(T_{5}-T_{6}\right)}{\log \left(\frac{r_{5}}{r_{6}}\right)}$

where $Q_{5}$ is the total heat transferred through the condenser tube (W), $r_{5}$ and $r_{6}$ are the radius $(\mathrm{m}), T_{6}$ is the average cold side condenser surface temperature $(\mathrm{K})$.

Hence $T_{5}-T_{6}=\frac{Q_{5}}{2 \pi k_{\text {metal }} L} \cdot \log \left(\frac{r_{5}}{r_{6}}\right)$

Coolant section Heat is transferred from condenser surface to the coolant fluid by means of convection: $Q_{6}=h_{c} .2 \pi r_{6} L\left(T_{6}-T_{7}\right)$

So $T_{6}-T_{7}=Q_{6} / h_{c} .2 \pi r_{6} L$

where $Q_{6}$ is the total heat transferred from the condenser tube to the cold fluid through convection (W), $r_{6}$ is the radius from core of the module to the condenser tube inner surface $(\mathrm{m}), T_{7}$ is the average bulk coolant stream temperature $(\mathrm{K})$, and $h_{c}$ is the heat transfer coefficient for cold channel $\left(\mathrm{W} / \mathrm{m}^{2} \mathrm{~K}\right)$.

Now combining Eqs. 2, 3, and 4:

$$
\begin{aligned}
T_{1}-T_{4}= & \frac{Q_{1}}{2 \pi r_{2} L h_{f}}+\left(\frac{Q_{2}-J h_{f g}}{2 \pi k_{m} L}\right) \\
& \log \left(\frac{r_{2}}{r_{3}}\right)+\left(\frac{Q_{3}-J h_{f g}}{2 \pi n k_{g} L_{g}}\right) \log \left(\frac{r_{3}}{r_{4}}\right)
\end{aligned}
$$

Now combining Eqs. 7, 8, and 9:
At steady state it is to be noted that the heat flow will be the same (Fig. 3) through all the sections. A heat transfer circuit is shown in Fig. 3 that resembles to an electrical circuit and shows that the heat transfer throughout the module is equal. That is:

$Q_{1}=Q_{2}=Q_{3}=Q_{4}=Q_{5}=Q_{6}$

So from Eqs. 10 and 11 heat flow can be written as,

$Q=\frac{\left(T_{1}-T_{7}\right)+J \cdot h_{f g}\left[\frac{\log \left(\frac{r_{2}}{r_{3}}\right)}{2 \pi k_{m} L}+\frac{\log \left(\frac{r_{3}}{r_{4}}\right)}{2 \pi n k_{g} L_{g}}\right]}{\left[\frac{1}{h_{p}}+\frac{1}{h_{f} \cdot 2 \pi r_{2} L}+\frac{\log \left(\frac{r_{2}}{r_{3}}\right)}{2 \pi k_{m} L}+\frac{\log \left(\frac{r_{3}}{r_{4}}\right)}{2 \pi n k_{g} L_{g}}\right]}$

From Eq. 1:

$$
T_{2}=T_{1}-\frac{\left(T_{1}-T_{7}\right)+J \cdot h_{f g}\left[\frac{\log \left(\frac{r_{2}}{r_{3}}\right)}{2 \pi k_{m} L}+\frac{\log \left(\frac{r_{3}}{r_{4}}\right)}{2 \pi n k_{g} L_{g}}\right]}{h_{f} \cdot 2 \pi r_{1} L\left[\frac{1}{h_{p}}+\frac{1}{h_{f} .2 \pi r_{2} L}+\frac{\log \left(\frac{r_{2}}{r_{3}}\right)}{2 \pi k_{m} L}+\frac{\log \left(\frac{r_{3}}{r_{4}}\right)}{2 \pi n k_{g} L_{g}}\right]}
$$

From Eq. 12:

$$
T_{4}=T_{7}+\frac{\left(T_{1}-T_{7}\right)+J \cdot h_{f g}\left[\frac{\log \left(\frac{r_{2}}{r_{3}}\right)}{2 \pi k_{m} L}+\frac{\log \left(\frac{r_{3}}{r_{4}}\right)}{2 \pi n k_{g} L_{g}}\right]}{h_{p}\left[\frac{1}{h_{p}}+\frac{1}{h_{f} \cdot 2 \pi r_{2} L}+\frac{\log \left(\frac{r_{2}}{r_{3}}\right)}{2 \pi k_{m} L}+\frac{\log \left(\frac{r_{3}}{r_{4}}\right)}{2 \pi n k_{g} L_{g}}\right]}
$$

The values of heat transfer coefficients for hot feed and cold fluid flow to be determined using the Nusselt number.

$$
\begin{aligned}
T_{4}-T_{7}= & \frac{Q_{4}}{\left\{\left(\sqrt{h_{d_{1}} \cdot P_{\text {fin }} \cdot K_{\text {fin }} \cdot A_{\mathrm{cs} . \mathrm{fin}} \cdot} \tanh (m b) \cdot\left(T_{4}-T_{5}\right) \eta_{\mathrm{fin}} \cdot n\right)+\frac{2 \pi k_{\mathrm{film}} L_{b} n\left(T_{4}-T_{5}\right)}{\log \left(\frac{r_{4}}{r_{5}}\right)}\right\}} \\
& +\left(\frac{Q_{5}}{2 \pi k_{\text {metal }} L}\right) \log \left(\frac{r_{5}}{r_{6}}\right)+\left(\frac{Q_{6}}{2 \pi r_{6} L h_{c}}\right)
\end{aligned}
$$

And $Q_{4}=h_{p}\left(T_{4}-T_{7}\right)$

where

$h_{p}=1 /\left(\frac{1}{\left\{\left(\sqrt{h_{d_{1}} \cdot P_{\text {fin }} \cdot K_{\text {fin }} \cdot A_{\text {cs.fin }} \cdot} \tanh (m b) \cdot\left(T_{4}-T_{5}\right) \eta_{f i n} \cdot n\right)+\frac{2 \pi k_{\text {film }} L_{b} n\left(T_{4}-T_{5}\right)}{\log \left(\frac{r_{4}}{r_{5}}\right)}\right\}}+\left(\frac{1}{2 \pi k_{\text {metal }} L}\right) \log \left(\frac{r_{5}}{r_{6}}\right)+\left(\frac{1}{2 \pi r_{6} L h_{c}}\right)\right)$
For laminar flow : $\mathrm{Nu}=1.86\left(\frac{\mathrm{Re} . \mathrm{Pr}}{x / D}\right)^{0.333}$ 
For turbulent flow : $\mathrm{Nu}=0.023 \mathrm{Re}^{0.8} \mathrm{Pr}$

The dimensionless number used here is: Reynold's number $\operatorname{Re}=\frac{\rho V D}{\mu}$, Prandtl number $\operatorname{Pr}=\frac{\mu C p}{k}$, and Nusselt number $N u=\frac{h l_{c}}{k}$.

\section{Mass transfer}

The overall process of distillate production involves the vaporization of the feed at the membrane surface and then diffusion through it. So, the amount of the vapors formed in HAGMD is dependent on the vapor pressure at membrane surface at feed side $P_{2}$ and that at the condensate film $P_{4}$ and can be written as (Khayet and Matsuura 2011c):

$J=\frac{\varepsilon P D_{w a}\left(P_{2}-P_{4}\right)}{R T_{m} b \cdot\left|P_{a}\right|_{\ln }}$

where $P_{2}$ and $P_{4}$ can be determined by the Antoine equation at the corresponding temperatures as (Elhenawy et al. 2020):

$P_{v}=\exp \left(23.196-\frac{3816.44}{T-46.13}\right)$

In Eq. (19), $\varepsilon$ is the membrane porosity, $R$ is the gas constant (J/kg.K), $D_{w a}$ is mass diffusivity coefficient $\left(\mathrm{m}^{2} / \mathrm{s}\right), b$ is the air gap width $(\mathrm{m}), T_{m}$ is the mean temperature $(\mathrm{K}), P$ is the total pressure $(\mathrm{Pa})$, and $\left|P_{a}\right|_{\ln }$ is the logarithmic mean of air pressure $(\mathrm{Pa})$.

The presence of the salt in the feed solution changes the vapor pressure at the membrane surface and can be accounted by the following equation (Elhenawy et al. 2019).

$P_{2}=(1-C M) P_{v}\left(T_{2}\right)$

Here CM is the mole solute concentration that can be calculated from Elhenawy et al. (2020);

$C M=\frac{S}{58.44}$ where $S$ is the concentration of the saline feed $(\mathrm{g} / \mathrm{L})$, in this case $\mathrm{NaCl}$, and 58.44 is the molar mass of sodium chloride ( $\mathrm{g} / \mathrm{mol})$.

Solving Eqs. 15, 16, and 19 total distillate flux can be calculated. A theoretical model was developed using MAT$\mathrm{LAB}$, and the above set of equations were solved using an iterative procedure to get the values of flux and temperatures at different operating conditions. Feed temperature and the cold channel temperature are always known. $T_{2}$ and $T_{4}$ are guessed initially, and after solving one process, we get the new temperature values for the same. The iterations are terminated and converged when the difference in the initial and calculated values is less than 0.00001 . The complete modeling steps are shown in a flowchart form in appendix 2 (Appendix 2).

\section{Details of HAGMD module and the membrane assembly preparation}

Figure 4 shows the actual picture of the HAGMD module after the membrane, condenser, and shell assembly. The module is insulated at the outer side to prevent heat loss to the surroundings with rock wool insulation. The picture shows the inlet and outlets for the feed and the cold stream. The bottom of the condenser tube and the permeate outlet is also visible in the picture to give the reader a complete idea of the HAGMD module. Table 1 shows the dimensional particulars of the HAGMD module. The properties and the details of the separating PTFE membrane are shown in Table 2.

\section{Experimental setup and experimentation methodology}

Figure 5 shows the schematic of the experimental setup. The experimental setup is viewed as three channels/circuits for the ease of understanding of the operation. The circuits are explained separately in the following subsections.

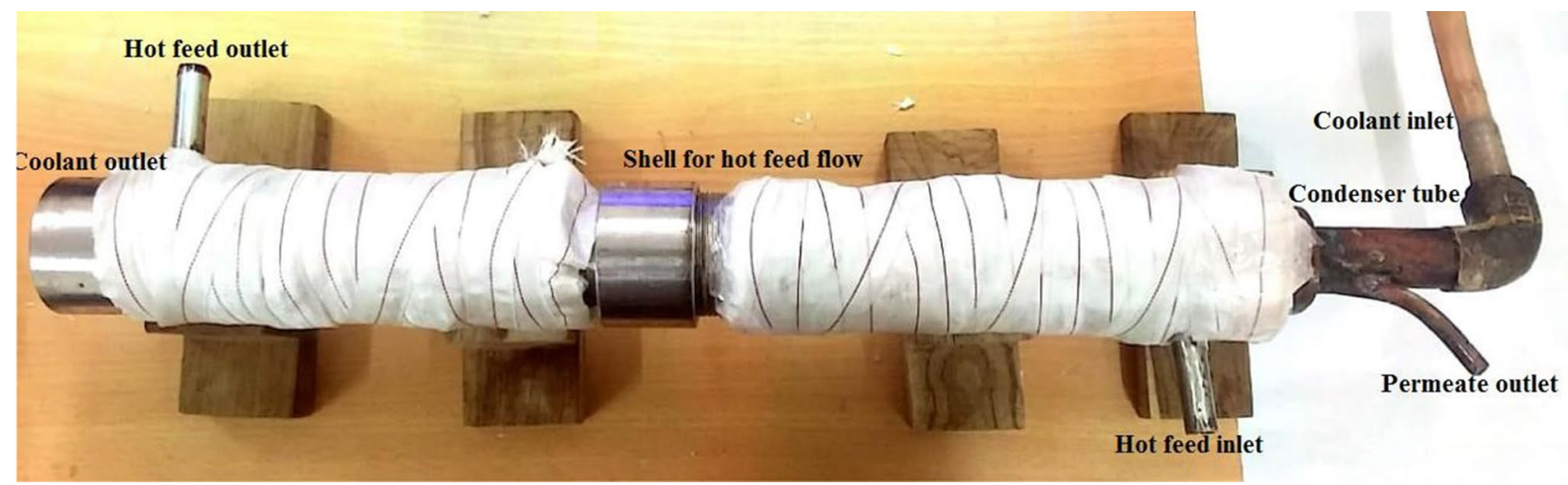

Fig. 4 Actual image of HAGMD module used in the present study 
Table 1 Dimensions of HAGMD system

\begin{tabular}{ll}
\hline Module parts & Dimension \\
\hline Condenser tube inner diameter & $15 \mathrm{~mm}$ \\
Number of fins & $1-35$ \\
Condenser material & Copper \\
Inner diameter of shell & $34 \mathrm{~mm}$ \\
Diameter of finned portion & $26 \mathrm{~mm}$ \\
Overall length of shell & $500 \mathrm{~mm}$ \\
\hline
\end{tabular}

Table 2 Properties of PTFE flat sheet membrane

\begin{tabular}{ll}
\hline Membrane characteristic & Value \\
\hline Polymer & Polytetrafluoroethylene (PTFE) \\
Pore size & $0.2 \mu \mathrm{m}$ \\
Thickness & $175 \mu \mathrm{m}$ \\
Structure & Supported on polypropylene base \\
Width & $85 \mathrm{~mm}$ \\
Porosity & $80 \%$ \\
Active membrane area & 0.012 \\
$\left(\mathrm{~m}^{2}\right)$ & \\
\hline
\end{tabular}

The variables were classified on the basis of their nature as operating and design variables. Table provides the working range and description of the same.

Feed circuit The feed circuit can be seen on the left side in the line sketch. The components in this circuit are the feedwater supply tank, feed pump, shell of HAGMD module, rotameter, thermocouples, and associated piping. The feedwater is heated in the feed tank that is a thermostatically controlled feed supply tank. The heated water at the desired temperature is supplied at the bottom of the HAGMD shell through a feed pump. The pump used here is a centrifugal pump (TAHA PMD 30) that is capable of circulating hot saline solutions at the desired temperatures. The flow rate of the feed stream is controlled and measured with the help of a rotameter, and the temperature at the module inlet and outlet is measured with the help of RTD thermocouples (PT-100) having an accuracy of $\pm 0.01{ }^{\circ} \mathrm{C}$. The feed salinity is measured with an electrical conductivity meter (systronics-360). After the module, the feed returns to the feed tank. The loss of the feed is replenished by adding extra feed with the desired salinity so that the salinity of the tank does not vary. The feed solution is prepared with laboratory-grade $\mathrm{NaCl}$ salt of the salinity of $20 \mathrm{gm} / \mathrm{liter}$. This resulted in salinity of the tank feed as $50,000 \mu \mathrm{s} / \mathrm{cm}$.

Coolant channel The right side of the schematic diagram in Fig. 5 shows the coolant channel. The components in this

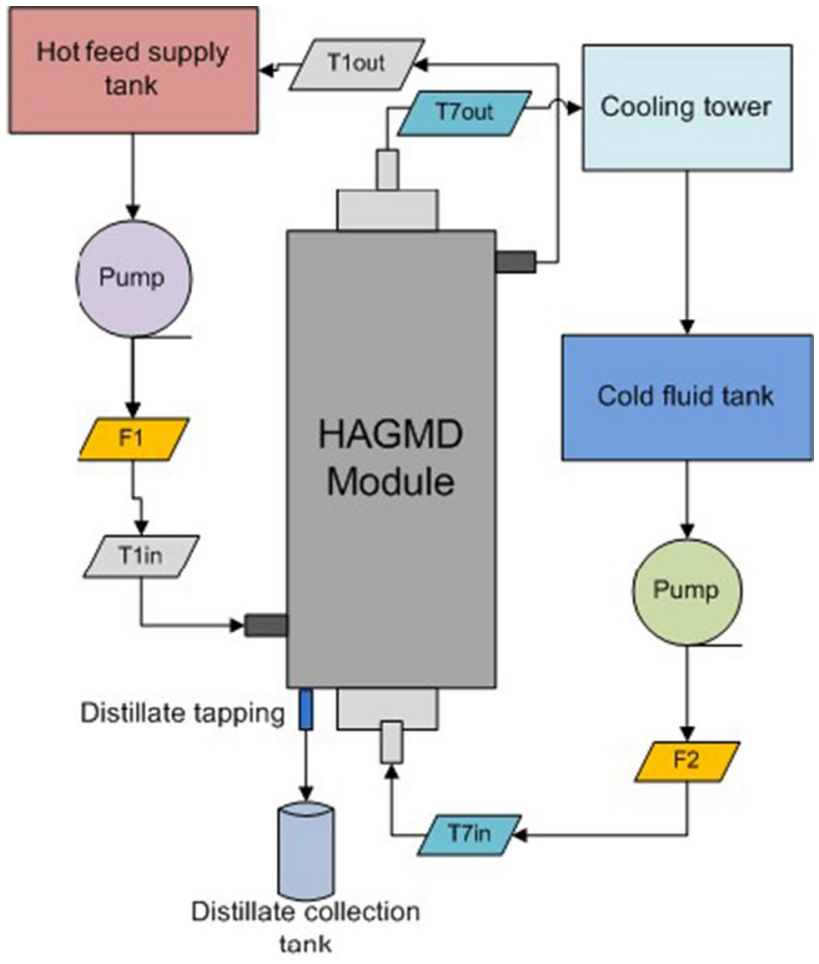

Fig. 5 Line sketch of HAGMD experimental setup

circuit are a cold fluid tank, coolant pump, condenser tube of HAGMD module, rotameter, thermocouples, and a cooling tower. The cold water tank contains the coolant water, in this case the regular tap water. The temperature of the cold water is in the range of $24-26^{\circ} \mathrm{C}$ and is not variable, as no chiller was used in this study. The cold water is supplied from the tank through a centrifugal pump to the condenser tube of HAGMD module. The temperatures are measured at the inlet and outlet of the condenser tube with the help of RTD thermocouples, and the flow rate is measured and controlled by rotameters. The cold water absorbs the heat in the condenser tube and becomes warm. To bring it back to the initial temperature, this extra heat is rejected in a cooling tower. The cooling tower is simple evaporative type in construction. After the cooling tower, the cold water returns to the cold fluid tank. Makeup water from the tap restores the loss of cold water.

Permeate channel The permeate condensed on the fins and the walls of the condenser surface rolls down toward the permeate tapping provided at the condenser bottom. The tapping opens in the collection jar, and the weight of the collected permeate is measured with the help of a digital weighing machine (LG-T3) with $\pm 0.001 \mathrm{gm}$ accuracy. The quality of the permeate is measured with the help of an electrical conductivity meter with the accuracy of $\pm 0.0001 \mu \mathrm{s} /$ 
$\mathrm{cm}$. It was observed that the salt rejection of the module was always greater than $99.7 \%$.

The permeate flux is considered as the first performance parameter that is used to measure and justify the system performance. For the HAGMD system this is calculated experimentally as:

$J_{w}=\frac{W}{A_{m} \cdot t}$

here $J_{w}$ is the permeate flux $\left(\mathrm{kg} / \mathrm{m}^{2} \mathrm{hr}\right), A_{m}$ is the active area of membrane $\left(\mathrm{m}^{2}\right), W$ is the collected flux's weight $(\mathrm{kg})$, and $t$ is the collection time for the collected permeate (hr). Gained output ratio is considered as the second performance parameter and is the ratio of total latent heat utilized by the useful permeate to the total thermal energy supplied by external energy source for heating the feed solution. Experimentally GOR is calculated as:

$\mathrm{GOR}=\frac{J_{w} \cdot h_{f g} \cdot A_{m}}{m \cdot c_{p} \cdot\left(T_{1 \text { in }}-T_{\text {1out }}\right)}$

here $m$ shows the feed flow rate through the module $(\mathrm{kg} / \mathrm{hr})$, $c_{p}$ is specific heat of the feed $(\mathrm{J} / \mathrm{kgK})$, and $h_{f g}$ is the latent heat of evaporation $(\mathrm{J} / \mathrm{kg})$ that is calculated as:

$h_{f g}=1.7535 . T_{m}+2024.3$

\section{Results and discussion}

The performance of the HAGMD system was determined experimentally as well as by model simulations. The results reflect the system performance under different operating and design conditions. The behavioral trend for the present HAGMD system is discussed below:

\section{Theoretical model validation}

The theoretical heat and mass transfer model presents an approach to determine the system performance under varying conditions. The model can be used wisely to predict the system behavior for the conditions which are even beyond the considered experimental range if the model is validated and tested finely within the operating range. The present theoretical model was validated using the experimental results under different operating and design conditions. The model is very well formulated by involving the operating and design variables into the physics and the thermal definitions of the system. For determining the values from the theoretical model, the procedure described in Appendix 2 is followed.
The validation results are presented by varying one design parameter and one operating parameter so that the effect of both can be successfully used for validating the results of the theoretical model with experimentation and vice versa. Figure 6 presents the comparison of theoretical and simulation results for permeate or distillate flux with feed temperature (FT) by also varying the number of fins (N). The other variables are fixed at their base values which are feed flow rate (FFR) at $2 \mathrm{lpm}$, cold flow rate (CFR) at $2 \mathrm{lpm}$, air gap width $(\mathrm{W})$ at $3 \mathrm{~mm}$, and length of the module (L) at $270 \mathrm{~mm}$ as mentioned in Table 3. The FT was varied from 45 to $75{ }^{\circ} \mathrm{C}$, and $\mathrm{N}$ was varied from 1 to 35 as mentioned in Table 3 . In a similar manner variation of distillate flux is presented with variable feed flow rate with the number of fins in Fig. 7. In this case, FT was fixed at $65^{\circ} \mathrm{C}$.

Table 4 shows the comparison of theoretical and simulated flux for other sets of parameters. The constant parameters for the table results are set at feed flow rate (FFR) at 2 $\mathrm{lpm}$, feed temperature (FT) at $65^{\circ} \mathrm{C}$, air gap width (W) at 3 $\mathrm{mm}$, and length of module (L) at $270 \mathrm{~mm}$.

The comparison of model and experimental results for GOR is also shown in Fig. 8. The parameters that were variable are feed temperature and the number of fins, while the constant variables for this case are feed flow rate (FFR) at $2 \mathrm{lpm}$, cold flow rate (CFR) at $2 \mathrm{lpm}$, air gap width $(W)$ at 3 $\mathrm{mm}$, and length of the module $(L)$ at $270 \mathrm{~mm}$, fixed at their base values as per Table 3 .

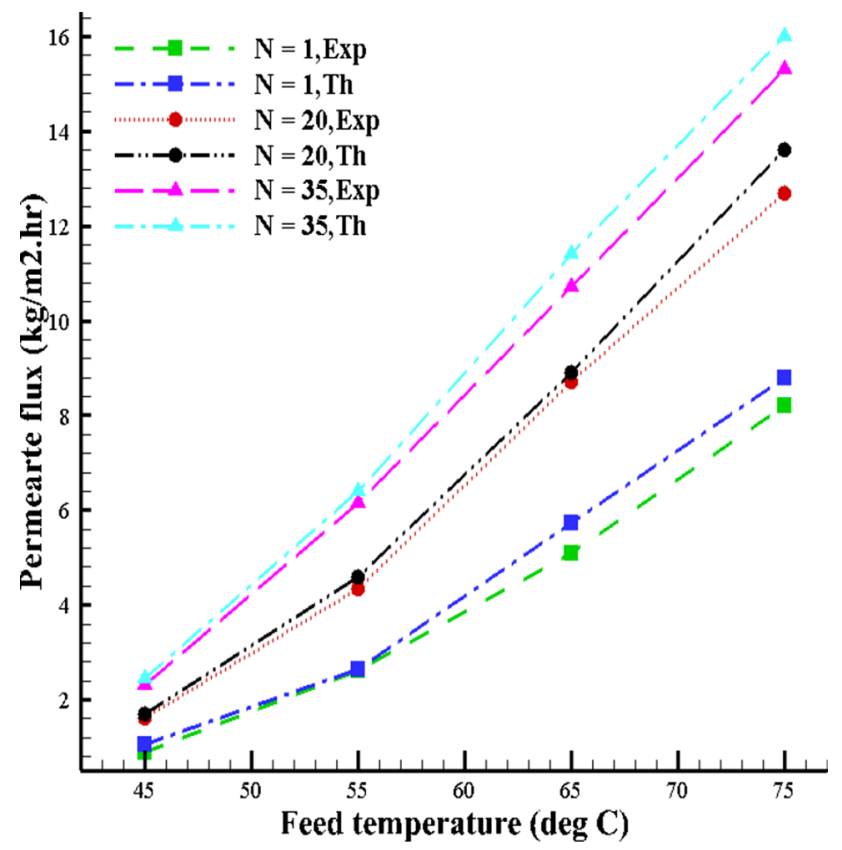

Fig. 6 Validation of theoretical model with experimentation for variable feed temperature 
Table 3 Experimental values of design and operational parameters

\begin{tabular}{lll}
\hline & Feed water & Cold water \\
\hline Operating parameters & Temperature & $45,55,65^{*}, 75^{\circ} \mathrm{C}$ \\
& & $24-26^{\circ} \mathrm{C}$ \\
& Flow rate & $1,2^{*}, 3 \mathrm{lpm} 1,2^{*}, 3 \mathrm{lpm}$ \\
& Salinity & $20 \mathrm{gm} / \mathrm{liter}$ Tap water \\
Design parameters & Height of fins & $1,3^{*}, 5,10,15,20 \mathrm{~mm}$ \\
& Number of fins & $1,20^{*}, 35$ \\
& Length of module & $200,270^{*}, 340,400 \mathrm{~mm}$
\end{tabular}

*Base line values of variables

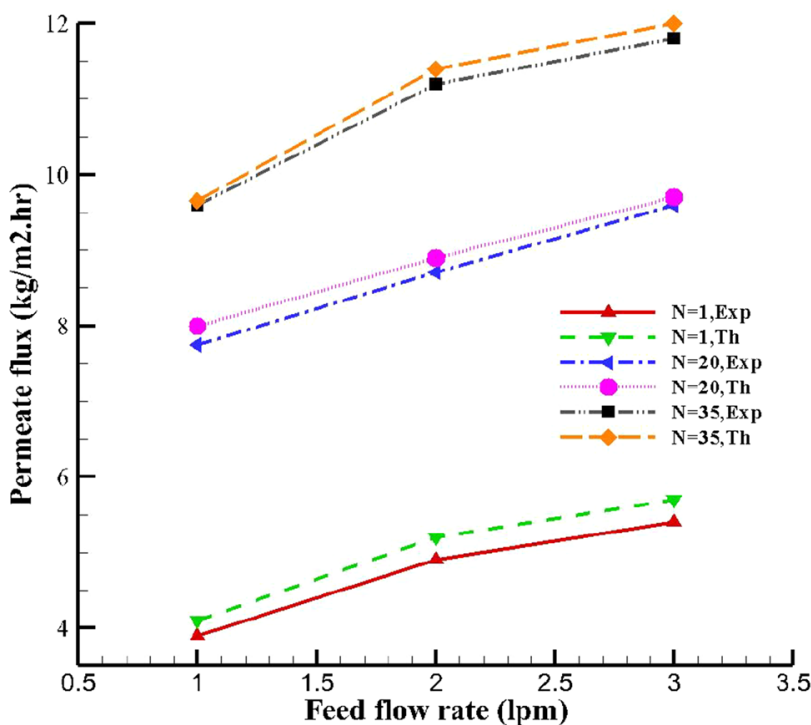

Fig. 7 Comparison of theoretical model with experimentation for different feed flow rate

Table 4 Comparison of permeate flux results from theoretical and experimental analysis

\begin{tabular}{lllll}
\hline $\begin{array}{l}\text { Cold flow } \\
\text { rate }(\mathrm{lpm})\end{array}$ & $\begin{array}{l}\text { Number } \\
\text { of fins }\end{array}$ & $\begin{array}{l}\text { Theoretical } \\
\text { flux }\left(\mathrm{kg} / \mathrm{m}^{2}\right. \\
\mathrm{hr})\end{array}$ & $\begin{array}{l}\text { Experimental } \\
\text { flux }\left(\mathrm{kg} / \mathrm{m}^{2} \mathrm{hr}\right)\end{array}$ & $\%$ Difference \\
\hline 1 & 20 & 7.0 & 6.8 & 2.9 \\
& 35 & 9.95 & 9.1 & 8 \\
2 & 20 & 8.9 & 8.7 & 2.1 \\
3 & 35 & 11.4 & 10.6 & 7.1 \\
& 20 & 10.74 & 10.5 & 1.6 \\
& 35 & 12.8 & 12.1 & 6 \\
\hline
\end{tabular}

For validation, the value of GOR is calculated from Eq. (24) for experimental values, while for calculating GOR from the theoretical model, the denominator of Eq. (24) was replaced by the expression for $Q_{1}$ from Eq. (2a) as both are equal if heat loss to the surrounding is neglected. It can

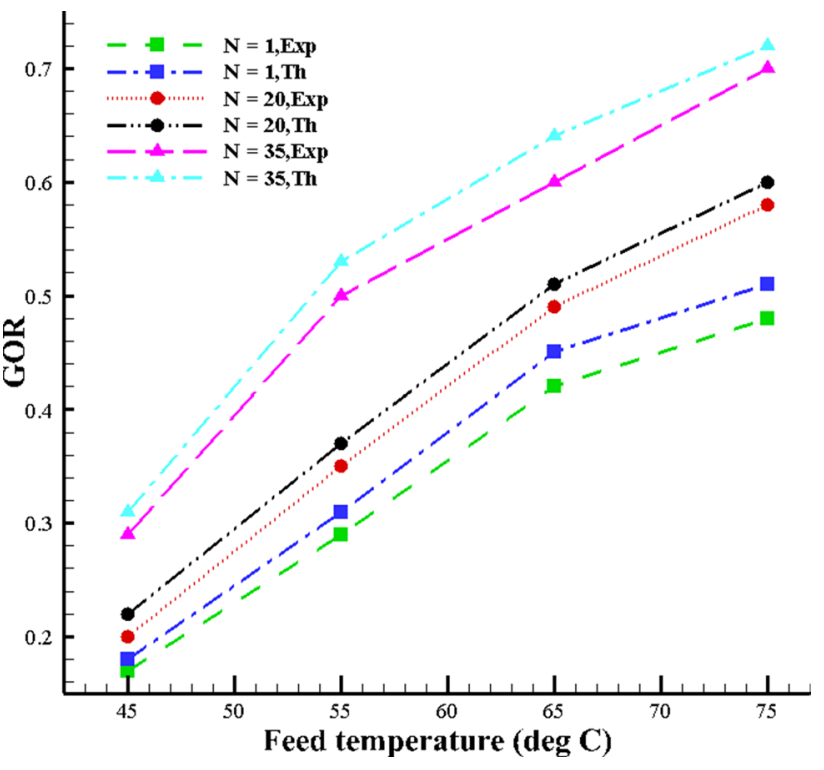

Fig. 8 Validation and comparison of GOR from experimental and theoretical results

be seen that the average deviation between the results from experimentation and model for permeate flux and GOR variation falls under an average of $5.5 \%$ that shows that the model is very well designed to predict the performance of the HAGMD system.

\section{Effect of operating parameters on the distillate flux}

\section{Feed temperature}

The most important parameter affecting the permeate flux in any MD system is the feed temperature due to its exponential relationship with vapor pressure according to the Antoine equation as stated earlier in Eq. (20) (Khayet and Cojocaru 2012). The vapor pressure difference across the membrane is the driving force for the permeate production (Khayet and Matsuura 2011b). An increase in the FT results in an increase in the permeate flux exponentially that can be seen from Fig. 9. The figure shows the experimental results for permeate flux with feed temperature as the variable for different values of feed flow rate and the number of fins, while the cold flow rate, air gap width, and length of the module are fixed at $2 \mathrm{lpm}, 3 \mathrm{~mm}$, and $270 \mathrm{~mm}$, respectively. Percentage error bars are also shown in the figure. Feed temperature is varied from 45 to $75{ }^{\circ} \mathrm{C}$. Figure shows that an increase in the FT along with the FFR increases the flux owing to an increase in the turbulence in feed channel that increases the heat transfer coefficient and therefore the heat transfer (Criscuoli et al. 2016). This results in reduced temperature polarization within the feed channel and increases the temperature at the membrane-feed interface and that ultimately 


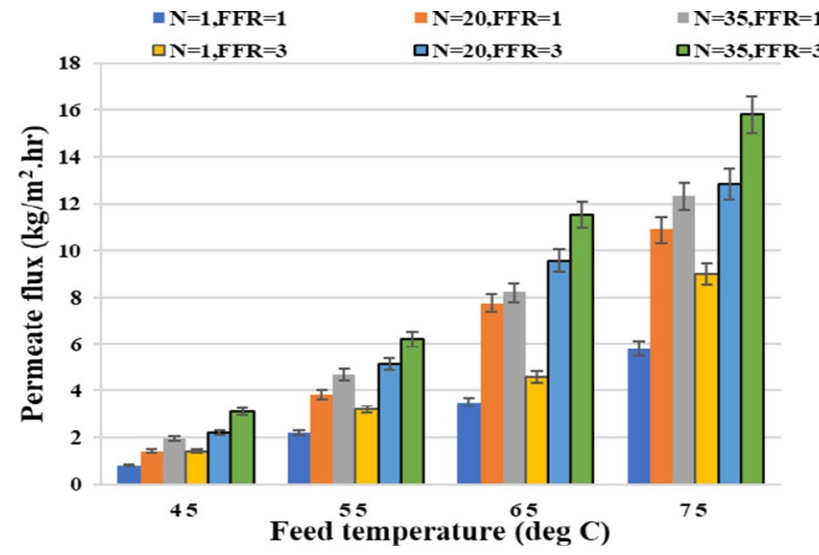

Fig. 9 Effect of FT on permeate flux ( $W=3 \mathrm{~mm}, L=270 \mathrm{~mm}$, $\mathrm{CFR}=2 \mathrm{lpm}$ )

helps in a further increased driving temperature difference; hence, the distillate flux increases. An increase in the FT also results in reduced feed viscosity, and this aids in the better mixing of the feed and further reduces the temperature polarization (Elhenawy et al. 2020). From the figure, it is clear that for any fixed temperature and FFR, permeate flux increases with the number of fins. The reason for this increase in flux is the increase in the total area available for condensation. The increased number of fins also results in a faster rate of heat transfer, and therefore, the driving temperature difference is higher as compared to that with only one fins.

\section{Feed flow rate}

Variation of permeate flux with FFR is shown in Fig. 10 with different feed temperatures and number of fins. The FFR is varied from 1 to $3 \mathrm{lpm}$, whereas the feed temperature considered for this analysis was $55^{\circ} \mathrm{C}$ and $75^{\circ} \mathrm{C}$. A number of fins considered were again 1, 20 and 35. Constant parameters were cold fluid temperature and flow rate at $24{ }^{\circ} \mathrm{C}$ and $2 \mathrm{lpm}$, respectively, while the fin height at $3 \mathrm{~mm}$ and the length of the module at $270 \mathrm{~mm}$.

Figure 10 indicates that for all values of feed temperatures and number of fins, there is an increase in permeate flux with FFR. The reason for the flux increase is due to an increase in the Reynolds number of the feed channel with the increase in the FFR that results in the flow regime turning from laminar to turbulent, and this increases the heat transfer coefficient. This increase in heat transfer coefficient results in an increase of the associated mass transfer coefficient at the membrane-feed interface that causes increased flux (Kerdi et al. 2020). Increased FFR also reduces the thickness of thermal and concentration boundary layers that reduce the consequence of temperature and concentration boundary layers. This increases the transmembrane temperature

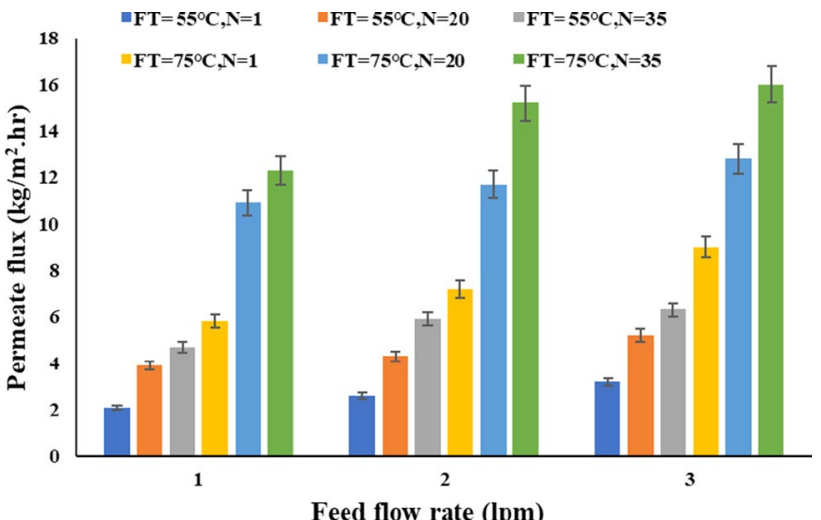

Fig. 10 Variation of permeate flux with FFR for different values of FT and N

difference due to the reduced temperature polarization and increases flux (Lee et al. 2019). With an increase in FFR, the retention time of feed over the membrane reduces, and that reduces the temperature drop of feed that is also a reason for increased driving temperature difference and thus increased distillate flux (Alkhudhiri and Hilal 2017). Table 5 shows the values for the increase in the experimental permeate flux for the different numbers of fins and the feed temperatures, when the FFR increases from 1 to $3 \mathrm{lpm}$. For any fixed number of fins, the percentage increase in the permeate flux is highest for $45{ }^{\circ} \mathrm{C}$ and then goes on decreasing for increasing temperatures. The reason for this is the opportunity for enthalpy difference, available at any temperature, goes on increasing with increasing temperature as the difference in vapor pressure increases. It can be seen that the lowest percentage increase is more than $15 \%$ that is appreciable. The percentage increase in the flux for the FFR of $2 \mathrm{lpm}$ is shown for $75{ }^{\circ} \mathrm{C}$ with the increase in the number of fins. When the

Table 5 Comparison of percentage increase in permeate flux different feed temperatures and number of fins

\begin{tabular}{|c|c|c|c|}
\hline \multirow[t]{2}{*}{ FT $\left({ }^{\circ} \mathrm{C}\right)$} & \multicolumn{3}{|c|}{$\begin{array}{l}\text { Number of fins } \\
(\% \text { increase in flux for increase of FFR from } \\
1 \text { lpm to } 3 \mathrm{lpm})\end{array}$} \\
\hline & 1 & 20 & 35 \\
\hline 45 & $42.85 \%$ & $36.36 \%$ & $36.77 \%$ \\
\hline 55 & $31.25 \%$ & $26.21 \%$ & $24.19 \%$ \\
\hline 65 & $23.91 \%$ & $18.93 \%$ & $28.69 \%$ \\
\hline 75 & $35.55 \%$ & $15.27 \%$ & $22.15 \%$ \\
\hline \multirow{3}{*}{$\begin{array}{c}75 \\
(\mathrm{FFR}=2 \\
\mathrm{lpm})\end{array}$} & & \multicolumn{2}{|c|}{$12 \%$} \\
\hline & \multicolumn{2}{|c|}{$52 \%$} & \\
\hline & \multicolumn{3}{|c|}{$255 \%$} \\
\hline
\end{tabular}


number of fins is increased from 20 to 35 , permeate flux increases by $12 \%$, while when it increases from 1 to 35 , the flux increases by $55 \%$. It shows that at any feed temperature and the number of fins, an increase in the FFR helps in improved permeate production rate.

\section{Cold flow rate}

The cold flow rate is a very important variable for the HAGMD system as the design modification is focused on the condenser design in this study, and the condenser conditions are mainly affected by the cold fluid conditions. The coolant temperature in this study is fixed, and therefore, the only variable to analyze the effect of, is the cold flow rate. The helical copper fins are machined on the condenser tube's outer surface, and therefore, the heat transfer from the fins is ultimately decided by the cold fluid flow. For higher cold flow rates, higher will be the heat transfer to the tube, through the fins, and therefore higher will be the condensation rate. This ultimately results in increased permeate flux as is indicated by Fig. 11 that illustrates the results for cold water flow rate on flux production. The permeate variation is shown for different FFR and the number of fins. Error bars are also shown on percentage basis. As stated by Banat (1998), depending on the design of the MD modules, the cold conditions can play an important role in affecting the system performance. In the present case, the increase in the CFR increases the flux as shown in Fig. 12 for all the values of FFR and number of fins. As the feed flow rate increases along with the cold flow rate, it results in an overall increase in the heat transfer coefficient on cold and hot fluid channels that reduces the thermal polarization and increases the flux (Wang et al. 2017).

With the increased number of fins, the condensation surface area increases and therefore the heat transfer rate of the

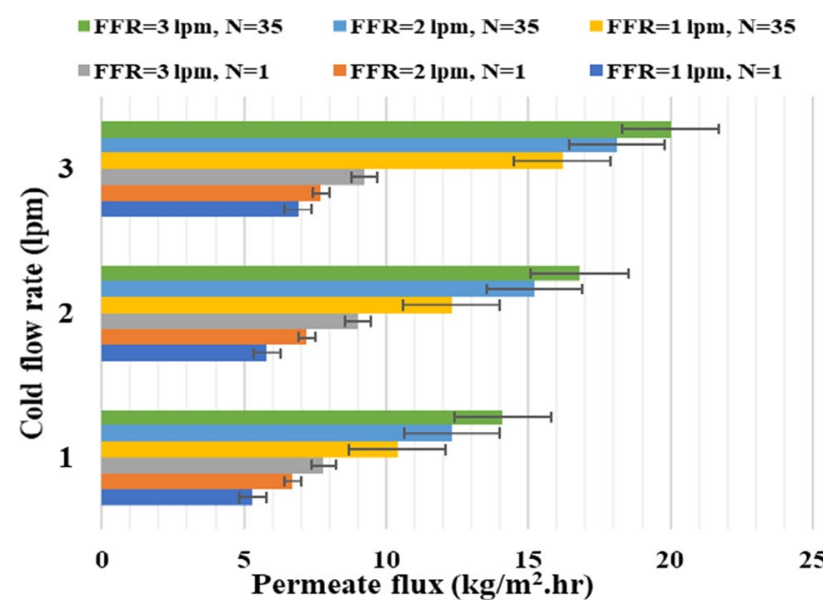

Fig. 11 Effect of CFR on permeate flux for different values of number of fins and FFR

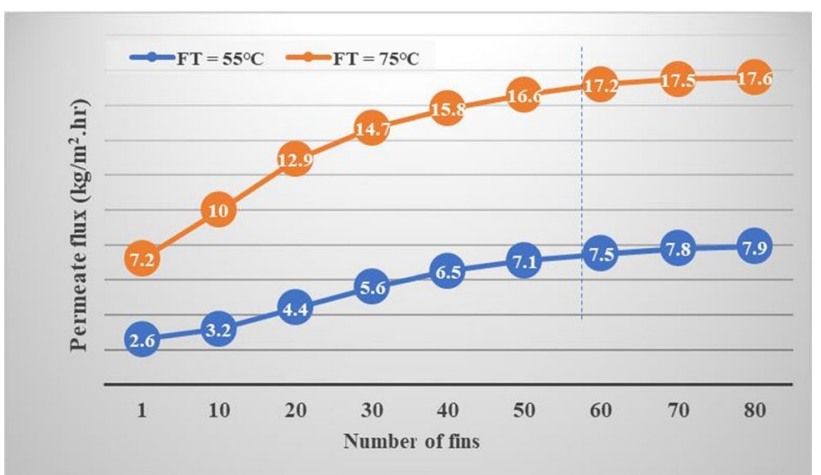

Fig. 12 Effect of increase in number of fins on permeate flux

latent heat of condensation to the condenser is increased (Shahu and Thombre 2021). And hence, the permeate flux for 35 fins is more than that with 1 fin. The percentage increase in the permeate flux for the same cold and feed flow rate is $41 \%$ and $54 \%$ for the HAGMD system with 20 and 35 number of fins, respectively, compared to only one fin, for the feed temperature of $75^{\circ} \mathrm{C}$ and $2 \mathrm{lpm}$ flow rate. When the CFR is increased from 1 to $2 \mathrm{lpm}$, the permeate flux for feed temperature of $75^{\circ} \mathrm{C}$ and $2 \mathrm{lpm}$ flow rate with 35 number of fins increased by $19 \%$, whereas when CFR increased from 1 to $3 \mathrm{lpm}$, the permeate increased by $32 \%$. This shows that cold conditions play a very important role in affecting the flux for the HAGMD system and influences the flux positively.

\section{Effect of design parameters on permeate flux}

\section{Number of fins}

The helical air gap membrane desalination module is designed with the provision of helical fins on the outer surface of the hollow condenser tube made up of conductive copper material. The helical fins are continuous, starting from the top of the condenser tube, and continues to the bottom (Shahu and Thombre 2021). The fins increase the total area available for condensation and help in increased transfer of condensation heat to the cold fluid apart from presenting a higher opportunity for the vapors to get condensed on the increased cold surface area. The fins are machined over the copper tube which is highly conductive and therefore help in increasing the heat transfer coefficient of the air gap. Swaminathan et al. (2016a) reported that the effect of increased air gap thermal conductivity is similar to the reduced air gap thickness. It has already been reported in the literature that reduced air gap thickness is always beneficial for increased permeate flux (Matheswaran et al. 2007; Woo et al. 2017; Alsalhy et al. 2018; Alkhudhiri et al. 2013; Banat 
et al. 2007), and therefore the presence of helical fins helps to increase the permeate flux as shown in Fig. 12.

Figure 12 shows the trend of permeate flux with an increasing number of fins and guides about the limit on the number of fins that results in better performance of the HAGMD system. To determine these values theoretical model was used. Feed temperature considered for this case is varied to $55^{\circ} \mathrm{C}$ and $75^{\circ} \mathrm{C}$, whereas the CFR and FFR are fixed at $2 \mathrm{lpm}$, air gap width that is equal to height of fins as $3 \mathrm{~mm}$ and length of HAGMD module as $270 \mathrm{~mm}$. The figure shows that an increase in the number of fins results in increased permeate flux. The result is in good agreement with the literature (Cheng et al. 2011; Swaminathan et al. $2016 \mathrm{~b}$ ) that suggested that with increase in the surface area for permeate collection, the permeate flux increases. This increase in flux goes constant after some point which shows that beyond a point, an increase in the number of fins will not be justifiable for the system, as this will not increase the permeate flux but only the manufacturing cost.

Figure 13 shows the variation of permeate flux for the variable number of fins. To show the cumulative effect of operating and design parameters, the effect of FT and CFR is also added in the same picture. The feed temperature is varied as $55^{\circ} \mathrm{C}$ and $75{ }^{\circ} \mathrm{C}$, whereas the cold flow rate is varied to its full range of $1-3 \mathrm{lpm}$. Other variables are fixed at FFR $2 \mathrm{lpm}$, air gap width that is equal to the height of fins as $3 \mathrm{~mm}$, and the length of the HAGMD module as 270 $\mathrm{mm}$. It can be seen from the figure that if the effect of all the variable parameters is analyzed for this case, the effect of increase in the number of fins is dominating to that of the cold flow rate after feed temperature. This implies that with an increasing number of fins, the permeate flux increases. The percentage rise in flux with the increased number of fins from 1 to 20 and 35 is $34 \%$ and $45 \%$, respectively, for the CFR $1 \mathrm{lpm}$, while for CFR 3lpm the same values are $46 \%$ and $58 \%$, respectively. This shows that a greater number of fins are always desirable for achieving higher flux. Bahar et al. (2015) also mentioned in a study with channeled coolant plate that higher number of fins are beneficial for the permeate flux.

\section{Height of fins}

For the present HAGMD system, the height of fins is defined as the length of fins starting from the wall of the condenser tube to the membrane surface, as the fins are touching to the membrane on the air gap side and therefore help in better sensible heat transfer to the cold water from the membrane. It is therefore clear that the air gap width is equal to the height of the fins. To determine the effect of the air gap width or in terms of design parameter, the height of fin, the analysis was performed and the theoretical model was used to calculate the flux values for different air gap widths of the HAGMD system. Figure 13 shows the variation of permeate flux for increasing fin heights for three different feed temperatures of $55^{\circ} \mathrm{C}$ and $65{ }^{\circ} \mathrm{C}$. The FFR was fixed at $2 \mathrm{lpm}$, while the results are presented for two different CFR of $1 \mathrm{lpm}$ and $3 \mathrm{lpm}$. Figure shows that for all the values of variable parameters, permeate flux firstly increases and then reduces after a peak that is slightly different for each feed temperatures and cold flow rates. This increase in flux is because with increasing air gap width, the height of fins is increasing. This renders more available condensation surface area and therefore increases the flux. The gap may be filled partially with permeate as well as with air, so the combined thermal conductivity of the gap (thermal conductivity of air, permeate, and copper fins together) increases with fin height that results in higher flux as also stated by Swaminathan et al. (2016b). After the peak the reason for reduced permeate flux may be due to presence of more air than permeate; therefore, the dominance of air in the gap increases. Therefore the resistance increased by the air filled in the gap dominates the overall process of vapor diffusion through the gap, and therefore, the flux reduces due to reduced combined thermal conductivity of the gap (Swaminathan et al. 2016b).

\section{Length of the module}

The length of the module is the active length of the module over which the membrane is wrapped. Figure 14 shows variation of permeate flux with length of the module. Number of fins is varied at 20 and 35. Other parameters are fixed to baseline values as indicated in Table 3 . It is clear from the figure that with the increase in the length of module, the

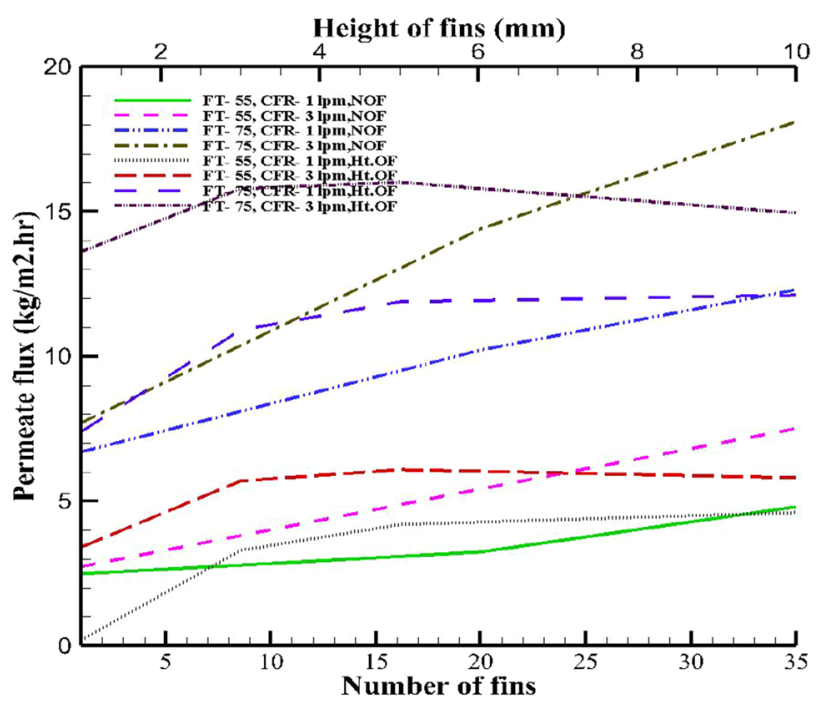

Fig. 13 Effect of number of fins and height of the fins on permeate flux for different values of feed temperature and cold flow rate 


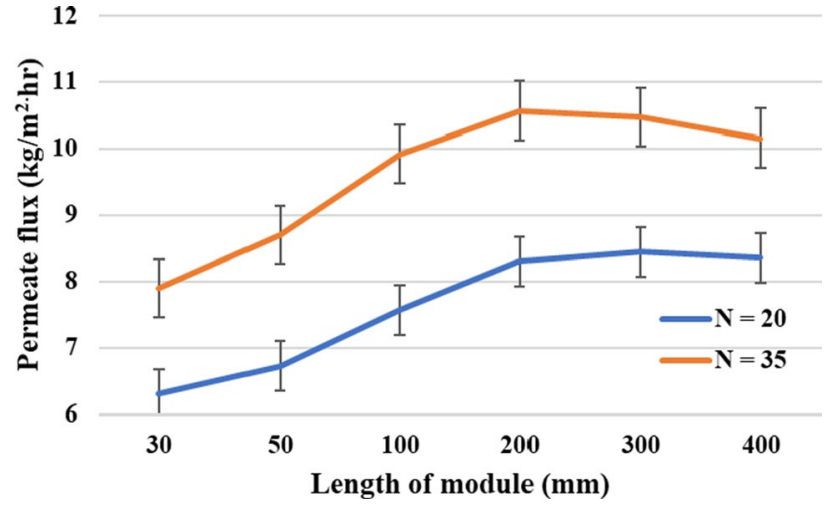

Fig. 14 Effect of length of the HAGMD module on permeate flux

permeate flux first increases and then reduces because of the increase in the pitch between the fins. The reason for reduction is the accumulation of more and more air between the consecutive fins with continuously increasing pitch that makes the gap lesser conductive. This reduces the coefficient of mass transfer in the gap and reduces the permeate flux. These findings are also in conjunction with the literature (Francis et al. 2013).

\section{Analysis of gained output ratio for HAGMD system}

Zhang et al. (2015) mentioned in their review that, for traditional MD processes, thermal efficiency and the gained output ratio (GOR) are similar (Swaminathan et al. 2018). Khayet and Matsuura mentioned that for simple effect systems, the value of GOR will be less than unity (Khayet and Matsuura 2011d). The present experimental facility is designed for laboratory-scale study and is not equipped with a heat recovery method. For ease of thermal efficiency comparison between the HAGMD and other systems from the literature, thermal performance of present HAGMD system is measured in the terms of GOR. The values of GOR presented in this discussion are calculated experimentally using equation (24), and the results showed that the values of GOR are in accordance with the literature for similar systems (Elhenawy et al. 2020; Aryapratama et al. 2016).

\section{Effect of operating parameters on GOR}

Operating parameters for the present study are varied to see their effects on gained output ratio (Fig. 15). In this case, the design parameters are set at their baseline values as indicated in Table 3. The range for feed temperature variation is from 45 to $75{ }^{\circ} \mathrm{C}$, while the FFR and CFR are varied to $1 \mathrm{lpm}$ and $3 \mathrm{lpm}$. As per equation (24), the major variables that affect the GOR of any MD system are FT and FFR. In agreement with the literature, the value of GOR for the

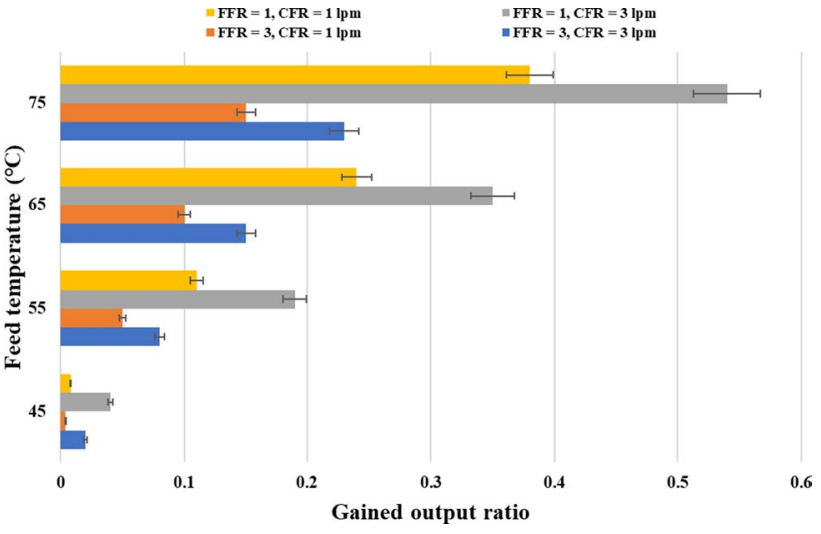

Fig. 15 Effect of operating parameters on GOR with design parameters set to base line value as per Table 3

HAGMD system also increases with FT and reduces with FFR (Swaminathan et al. 2018; Zuo et al. 2011). The reason for this is that with an increase in the feed temperature, the latent heat available at the feed-membrane surface interface increases. As discussed earlier, at higher FT the vapor pressure is higher that results in higher permeate flux. Also due to higher FT, thickness of the boundary layer decreases due to reduced feed viscosity, and the effect of temperature polarization weakens that increases the vaporization at membrane surface; hence, higher GOR can be achieved with higher feed temperature (Liu et al. 2016). With increment of FFR, the value of GOR decreases. The reason for this reduction is the reduction of residence time that results in lower sensible heat transfer from feed fluid to the cold stream and therefore lower GOR (Geng et al. 2014, 2016).

\section{Effect of design parameters on GOR}

To study the effectiveness of the present design modification in terms of thermal energy performance, the effect of design parameters is analyzed on GOR. Figure 16 shows the effect of fin height and number of fins on GOR with all other parameters fixed at their baseline values as indicated in Table 3.

Increasing the height of fins refers to an increase in the air gap width. Increase in the air gap width results in the presence of more air and then the permeate. This reduces the combined thermal conductivity of the gap and reduces the GOR, as also found in literature (Aryapratama et al. 2016; Singh and Sirkar 2012). With higher number of fins, GOR increases as the gap becomes more conductive; this facilitates the heat transfer to the cold fluid and therefore results in higher GOR. The effect of module length with fixed number of fins, on GOR, is increasing with increase in module length. The reason for this increase is that for constant number of fins, the increase in module length results in

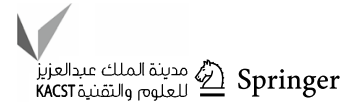




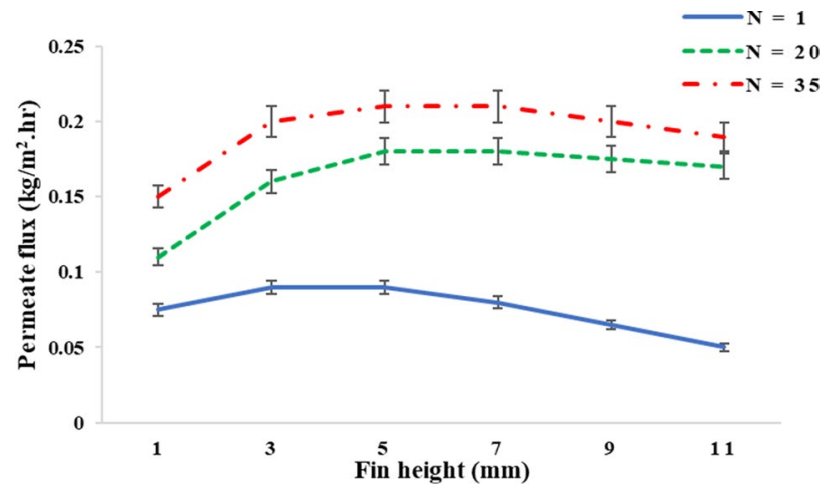

Fig. 16 Effect of design parameters on GOR with operating parameters fixed to the baseline values

increased pitch between the fins. This provides more surface area for condensation and results in higher GOR. The result is in agreement with the literature (Summers et al. 2012).

\section{Comparison of HAGMD performance with literature}

The present study is focused on the condenser design modification over the conventional AGMD systems to determine the system performance. The performance of any MD system depends on the number of parameters related specifically to the properties of membrane, feed fluid, feed channel, condenser side, and air gap conditions. It is difficult to compare the system performance with existing solutions in the literature, as every system considers different operating and design conditions. Still a comparison is summarized in Table 6 on the basis of literature focused only at modifications focused at air gap conditions and condenser design for AGMD modules. Values of permeate flux and energy efficiency indicators (GOR and STEC) are compared with existing literature for different operating and design conditions. For better benchmarking of present study against the literature the best operating condition for comparison is selected that are most close to the mentioned values of feed temperature $75^{\circ} \mathrm{C}$, cold fluid temperature $25^{\circ} \mathrm{C}$ and feed flow rate of $3 \mathrm{lpm}$. Similar design conditions were selected to the best possible way for comparison.

It should be noted that the performance of HAGMD system shows the highest value for permeate flux after superhydrophobic surfaces (Elhenawy et al. 2020), but the design parameters for both the systems are different and the most important of the studied design parameters, that is the air gap width, may be one of the major factor to cause this variation as in the compared study the air gap width is $1 \mathrm{~mm}$, while in present study it is $3 \mathrm{~mm}$ (lowest).
Energy efficiency performance of AGMD system is also differently studied in the selected studies and just to show a measure of system performance with respect to energy considerations, all the three parameters that specify the energy performance of any system (GOR/ $\eta$ th/ STEC) are mentioned here in the table, and it can give the reader a fair idea about the system's effectiveness for energy utilization.

\section{Conclusion and future scope}

A helical air gap membrane distillation module was developed based on AGMD design. The helical fins are machined on the outer surface of a copper condenser tube. The provision of fins results in increased surface area for condensation and therefore results in higher permeate flux and gained output ratio. The following important conclusions are drawn from the present study that describes the system behavior in the best conditions. Also suggested are the future possibilities to improve the system performance further.

(a) A detailed analysis of the helical air gap membrane distillation module is performed by considering the variation of a large number of operating and design parameters. Feed temperature, cold flow rate, and feed flow rate are defined as the operating parameters, and the number of fins, height of the fins, and the length of module are considered as the design variables for the system.

(b) A detailed theoretical model was developed to describe the heat and mass transfer in the helical AGMD module for the first time in the literature with the cylindrical coordinate scheme for MD systems. The model is validated with the experimental values for the same sets of operating parameters and found to be in excellent agreement with a maximum of $8 \%$ deviation for the permeate flux and 5.5\% deviation for the GOR.

(c) Increment of the permeate flux for increase in the number of fins from 1 to 35 is $58 \%$, while the GOR is increased by $29 \%$ that shows that the fins help in improved performance of the system.

(d) The performance of the system is found as per the literature for variation of operating parameters. The permeate flux increases with feed temperature, feed and cold flow rates to varying degrees. The effect of design parameters on the permeate flux is found to affect positively with the number of fins, but with the height of fins and length of module similar trend is observed to increase the flux initially, and then it reduces.

(e) It is suggested that with fixed feed, and cold fluid temperatures, it is advisable to keep the cold flow rate to higher levels, lower fin heights, and a higher number of fins to increase the permeate flux. 
Table 6 Comparison of the system performance for HAGMD and other AGMD modules

\begin{tabular}{|c|c|c|c|c|c|c|c|}
\hline $\begin{array}{l}\text { Module configu- } \\
\text { ration }\end{array}$ & $\begin{array}{l}\text { Membrane } \\
\text { material }\end{array}$ & Salinity & $\begin{array}{l}\text { Operating condi- } \\
\text { tions }\end{array}$ & $\begin{array}{l}\text { Design condi- } \\
\text { tions }\end{array}$ & $\begin{array}{l}\text { Maximum } \\
\text { flux }\left(\mathrm{Kg} / \mathrm{m}^{2}\right. \\
\mathrm{hr})\end{array}$ & $\begin{array}{l}\mathrm{GOR} / \eta_{\mathrm{th}} / \mathrm{STEC} \\
(\mathrm{kWh} / \mathrm{m} 3)\end{array}$ & References \\
\hline $\begin{array}{l}\text { Spiral wound } \\
\text { PGMD system }\end{array}$ & $\begin{array}{l}\text { PTFE Mem- } \\
\text { brane }\end{array}$ & $3.5 \mathrm{wt} \%$ & $\begin{array}{l}T_{\text {cold Side }}=20^{\circ} \mathrm{C} \\
T_{\text {feed side }}=75^{\circ} \mathrm{C} \\
Q_{\text {feed }}=6.6 \mathrm{lpm}\end{array}$ & $\begin{array}{l}\text { Solar thermal } \\
\text { energy by } \\
\text { using flat-plat } \\
\text { collectors }\end{array}$ & 1.5 & STEC; 255.8 & $\begin{array}{r}\text { Swaminathan } \\
\text { et al. (2018) }\end{array}$ \\
\hline $\begin{array}{c}\text { Flat plate } \\
\text { module }\end{array}$ & $\begin{array}{l}\text { PTFE Mem- } \\
\text { brane }\end{array}$ & $42 \mathrm{gm} / \mathrm{L}$ & $\begin{array}{l}T_{\text {cold Side }}=40^{\circ} \mathrm{C} \\
T_{\text {feed side }}=70^{\circ} \mathrm{C} \\
Q_{\text {feed }}=Q_{\text {cold }}=1.5 \\
\quad \text { lpm }\end{array}$ & $\begin{array}{l}\text { Multi-stage } \\
\text { air gap MD } \\
\text { reversal design } \\
\text { coupled with } \\
\text { natural/Forced } \\
\text { cooling system }\end{array}$ & 0.20 & GOR; 0.11 & $\begin{array}{c}\text { Khayet and Mat- } \\
\text { suura (2011a) }\end{array}$ \\
\hline $\begin{array}{l}\text { Hollow fiber } \\
\text { module }\end{array}$ & $\begin{array}{l}\text { TIPS-ipp hollow } \\
\text { fiber mem- } \\
\text { branes }\end{array}$ & $30 \mathrm{gm} / \mathrm{L}$ & $\begin{array}{l}T_{\text {cold Side }}=30^{\circ} \mathrm{C} \\
T_{\text {feed side }}=75^{\circ} \mathrm{C} \\
Q_{\text {feed }}=Q_{\text {cold }}=0.25 \\
\text { lpm }\end{array}$ & $\begin{array}{l}\text { Parallel hollow } \\
\text { fiber mem- } \\
\text { branes with } \\
\text { heat exchange } \\
\text { hollow fibers }\end{array}$ & 5.0 & Not studied & Geng et al. (2016) \\
\hline $\begin{array}{c}\text { Flat plate } \\
\text { module }\end{array}$ & $\begin{array}{l}\text { PVDF mem- } \\
\text { brane }\end{array}$ & - & $\begin{array}{l}T_{\text {cold Side }}=13^{\circ} \mathrm{C} \\
T_{\text {feed side }}=75^{\circ} \mathrm{C} \\
Q_{\text {feed }}=13.2 \mathrm{lpm} \\
Q_{\text {cold }}=10.8 \mathrm{lpm}\end{array}$ & $\begin{array}{l}\text { Silanized copper } \\
\text { oxide (Cuo) } \\
\text { nanoscale } \\
\text { superhydro- } \\
\text { phobic surface }\end{array}$ & 31 & Not studied & $\begin{array}{l}\text { Elhenawy et al. } \\
\text { (2020) }\end{array}$ \\
\hline $\begin{array}{r}\text { Flat Plate } \\
\text { Module }\end{array}$ & $\begin{array}{l}\text { PTFE Mem- } \\
\text { brane }\end{array}$ & $61,400 \mu \mathrm{s} / \mathrm{cm}$ & $\begin{array}{l}T_{\text {cold Side }}=20{ }^{\circ} \mathrm{C} \\
T_{\text {feed side }}=75^{\circ} \mathrm{C} \\
Q_{\text {feed }}=Q_{\text {cold }}=1.5 \\
\quad \text { lpm }\end{array}$ & $\begin{array}{l}\text { Material gap } \\
\text { membrane } \\
\text { distillation } \\
\text { by filling the } \\
\text { air gap with } \\
\text { polypropylene } \\
\text { (PP) mesh, } \\
\text { Polyurethane } \\
\text { (Sponge), De- } \\
\text { Ionized water } \\
\text { and sand }\end{array}$ & 17 & Not studied & $\begin{array}{l}\text { Khayet and Cojo- } \\
\text { caru (2012) }\end{array}$ \\
\hline $\begin{array}{l}\text { Cylindrical } \\
\text { module }\end{array}$ & $\begin{array}{l}\text { PTFE mem- } \\
\text { brane }\end{array}$ & $5 \mathrm{gm} / \mathrm{L}$ & $\begin{array}{l}T_{\text {cold }} \text { Side }=30{ }^{\circ} \mathrm{C} \\
T_{\text {feed }} \text { side }=60{ }^{\circ} \mathrm{C} \\
Q_{\text {feed }}=1.5 \mathrm{lpm} \\
Q_{\text {cold }}=1.5 \mathrm{lpm}\end{array}$ & $\begin{array}{l}\text { Cylindrical air } \\
\text { gap membrane } \\
\text { distillation } \\
\text { module }\end{array}$ & 3.5 & STEC; 281.25 & $\begin{array}{l}\text { Alkhudhiri and } \\
\text { Hilal (2017) }\end{array}$ \\
\hline $\begin{array}{l}\text { Hollow fiber } \\
\text { module }\end{array}$ & $\begin{array}{l}\text { PP/PVDF Mem- } \\
\text { brane }\end{array}$ & $1 \% \mathrm{Nacl}$ & $\begin{array}{l}T_{\text {cold Side }}=20{ }^{\circ} \mathrm{C} \\
T_{\text {feed side }}=75^{\circ} \mathrm{C} \\
Q \text { feed }=0.075 \mathrm{lpm}, \\
Q_{\text {cold }}=0.15 \mathrm{lpm}\end{array}$ & $\begin{array}{l}\text { Two-hollow- } \\
\text { fiber-set } \\
\text { AGMD mod- } \\
\text { ules in series }\end{array}$ & 11 & Not studied & $\begin{array}{l}\text { Singh and Sirkar } \\
\text { (2012) }\end{array}$ \\
\hline $\begin{array}{l}\text { Spiral wound } \\
\text { modules }\end{array}$ & PE Membrane & $20,000 \mu \mathrm{s} / \mathrm{cm}$ & 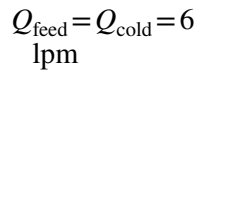 & $\begin{array}{l}\text { Two multi-enve- } \\
\text { lopes spiral } \\
\text { wound AGMD } \\
\text { modules } \\
\text { connected in } \\
\text { parallel }\end{array}$ & 11 & GOR; 0.95 & $\begin{array}{l}\text { Banat and } \\
\text { Simandl (1999) }\end{array}$ \\
\hline $\begin{array}{l}\text { Hollow fiber } \\
\text { module }\end{array}$ & $\begin{array}{l}\text { PVDF mem- } \\
\text { branes }\end{array}$ & - & $\begin{array}{l}T_{\text {cold Side }}=60{ }^{\circ} \mathrm{C} \\
T_{\text {feed side }}=75^{\circ} \mathrm{C} \\
Q_{\text {feed }}=0.06 \mathrm{lpm}\end{array}$ & $\begin{array}{l}\text { Double-pipe air } \\
\text { gap membrane } \\
\text { distillation } \\
\text { module }\end{array}$ & 3.5 & GOR; 2.5 & $\begin{array}{l}\text { M.C. Garciá } \\
\text {-Payo, M.A. } \\
\text { Izquierdo-Gil, } \\
\text { C. Fernández- } \\
\text { Pineda (2000) }\end{array}$ \\
\hline $\begin{array}{l}\text { Tubular mem- } \\
\text { brane module }\end{array}$ & $\begin{array}{l}\text { PTFE Mem- } \\
\text { brane }\end{array}$ & $0.55 \% \mathrm{Nacl}$ & $\begin{array}{l}T_{\text {cold Side }}=50^{\circ} \mathrm{C} \\
T_{\text {feed side }}=75^{\circ} \mathrm{C} \\
Q_{\text {feed }}=Q_{\text {cold }}=5 \\
\text { lpm }\end{array}$ & $\begin{array}{l}\text { Finned tubular } \\
\text { AGMD-based } \\
\text { module }\end{array}$ & 16 & Not studied & $\begin{array}{r}\text { Izquierdo-Gil } \\
\text { et al. (1999) }\end{array}$ \\
\hline
\end{tabular}


Table 6 (continued)

\begin{tabular}{|c|c|c|c|c|c|c|c|}
\hline $\begin{array}{l}\text { Module configu- } \\
\text { ration }\end{array}$ & $\begin{array}{l}\text { Membrane } \\
\text { material }\end{array}$ & Salinity & $\begin{array}{l}\text { Operating condi- } \\
\text { tions }\end{array}$ & $\begin{array}{l}\text { Design condi- } \\
\text { tions }\end{array}$ & $\begin{array}{l}\text { Maximum } \\
\text { flux }\left(\mathrm{Kg} / \mathrm{m}^{2}\right. \\
\mathrm{hr})\end{array}$ & $\begin{array}{l}\mathrm{GOR} / \eta_{\mathrm{th}} / \mathrm{STEC} \\
(\mathrm{kWh} / \mathrm{m} 3)\end{array}$ & References \\
\hline $\begin{array}{l}\text { Hollow fiber } \\
\text { module }\end{array}$ & PP membrane & $3.5 \% \mathrm{Nacl}$ & $\begin{array}{l}T_{\text {cold Side }}=20^{\circ} \mathrm{C} \\
T_{\text {feed side }}=75^{\circ} \mathrm{C} \\
Q_{\text {feed }}=0.4 \mathrm{lpm} \\
Q_{\text {cold }}=0.31 \mathrm{pm}\end{array}$ & $\begin{array}{l}\text { Multiple cool- } \\
\text { ing channels } \\
\text { network }\end{array}$ & 8.5 & $\eta_{\mathrm{th}}=82 \%$ & $\begin{array}{l}\text { Moejes et al. } \\
\text { (2020) }\end{array}$ \\
\hline $\begin{array}{l}\text { Hollow fiber } \\
\text { module }\end{array}$ & $\begin{array}{l}\text { PTFE mem- } \\
\text { brane }\end{array}$ & $253 \mathrm{ppm}$ & $\begin{array}{l}T_{\text {cold Side }}=20{ }^{\circ} \mathrm{C} \\
T_{\text {feed side }}=80{ }^{\circ} \mathrm{C} \\
Q_{\text {feed }}=4 \mathrm{lpm} \\
Q_{\text {cold }}=0.3 \mathrm{lpm}\end{array}$ & $\begin{array}{l}\text { Vacuum-air gap } \\
\text { membrane } \\
\text { distillation }\end{array}$ & 11.87 & GOR; 1.01 & $\begin{array}{l}\text { Szczerbińska } \\
\text { et al. (2017) }\end{array}$ \\
\hline $\begin{array}{l}\text { Tubular mem- } \\
\text { brane module }\end{array}$ & $\begin{array}{l}\text { PTFE mem- } \\
\text { brane }\end{array}$ & $20 \mathrm{gm} / \mathrm{L}$ & $\begin{array}{l}T_{\text {cold Side }}=24^{\circ} \mathrm{C} \\
T_{\text {feed side }}=75^{\circ} \mathrm{C} \\
Q_{\text {feed }}=Q_{\text {cold }}=3 \\
\quad \text { lpm }\end{array}$ & $\begin{array}{l}\text { Helically finned } \\
\text { copper con- } \\
\text { denser }\end{array}$ & 20 & GOR; 0.11 & This study \\
\hline
\end{tabular}

(f) It is recommended that future studies should aim at an internal heat recovery method for improved GOR. Economic analysis should be performed focusing on higher permeate production and GOR with cheaper material for condenser and fins to decrease the overall system cost. It is also suggested that a combination of condenser material and fins material should be searched that will reduce the manufacturing cost and result in an economic system with better performance.

Supplementary Information The online version contains supplementary material available at https://doi.org/10.1007/s13201-021-01567-2.

Funding The research was supported by Visvesvaraya National Institute of Technology, Nagpur, India.

Code availability Copyright published for the theoretical heat and mass transfer 1-D MATLAB code for this system SW-14571/2021.

\section{Declarations}

Conflict of interest Authors declare no conflict of interest.

Open Access This article is licensed under a Creative Commons Attribution 4.0 International License, which permits use, sharing, adaptation, distribution and reproduction in any medium or format, as long as you give appropriate credit to the original author(s) and the source, provide a link to the Creative Commons licence, and indicate if changes were made. The images or other third party material in this article are included in the article's Creative Commons licence, unless indicated otherwise in a credit line to the material. If material is not included in the article's Creative Commons licence and your intended use is not permitted by statutory regulation or exceeds the permitted use, you will need to obtain permission directly from the copyright holder. To view a copy of this licence, visit http://creativecommons.org/licenses/by/4.0/.

\section{References}

Alkhudhiri A, Hilal N (2017) Air gap membrane distillation: a detailed study of high saline solution. Desalination 403:179-186. https:// doi.org/10.1016/j.desal.2016.07.046

Alkhudhiri A, Darwish N, Hilal N (2013) Produced water treatment: Application of Air Gap Membrane Distillation. Desalination 309:46-51. https://doi.org/10.1016/j.desal.2012.09.017

Alsalhy QF, Ibrahim SS, Hashim FA (2018) Experimental and theoretical investigation of air gap membrane distillation process for water desalination. Chem Eng Res Des 130:95-108. https://doi.org/10. 1016/j.cherd.2017.12.013

Aryapratama R, Koo H, Jeong S, Lee S (2016) Performance evaluation of hollow fiber air gap membrane distillation module with multiple cooling channels. Desalination 385:58-68. https://doi. org/10.1016/j.desal.2016.01.005

Asbik M, Ansari O, Bah A, Zari N, Mimet A, El-Ghetany H (2016) Exergy analysis of solar desalination still combined with heat storage system using phase change material (PCM). Desalination 381:26-37. https://doi.org/10.1016/j.desal.2015.11.031

Bahar R, Hawlader MNA, Ariff TF (2015) Channeled coolant plate: A new method to enhance freshwater production from an air gap membrane distillation (AGMD) desalination unit. Desalination 359:71-81. https://doi.org/10.1016/j.desal.2014.12.031

Banat FA, Simandl J (1998) Desalination by membrane distillation: a parametric study. Sep Sci Technol 33:201-226. https://doi.org/10. 1080/01496399808544764

Banat FA, Simandl J (1999) Membrane distillation for dilute ethanol: separation from aqueous streams. J Memb Sci 163:333-348. https://doi.org/10.1016/S03767388(99)00178-7

Banat F, Jwaied N, Rommel M, Koschikowski J, Wieghaus M (2007) Desalination by a "compact SMADES" autonomous solar powered membrane distillation unit. Desalination 217:29-37. https:// doi.org/10.1016/j.desal.2006.11.028

Cabassud C, Wirth D (2003) Membrane distillation for water desalination: how to chose an appropriate membrane? Desalination 157:307-314. https://doi.org/10.1016/S0011-9164(03)00410-7

Charfi K, Khayet M, Safi MJ (2010) Numerical simulation and experimental studies on heat and mass transfer using sweeping gas membrane distillation. Desalination 259:84-96. https://doi.org/ 10.1016/j.desal.2010.04.028 
Cheng LH, Wu PC, Chen J (2009) Numerical simulation and optimal design of AGMD-based hollow fiber modules for desalination. Ind Eng Chem Res 48:4948-4959. https://doi.org/10.1021/ie800832z

Cheng L-H, Lin Y-H, Chen J (2011) Enhanced air gap membrane desalination by novel finned tubular membrane modules. J Memb Sci 378:398-406. https://doi.org/10.1016/j.memsci.2011.05.030

Criscuoli A, Carnevale MC, Drioli E (2016) Study of the performance of a membrane-based vacuum drying process. Sep Purif Technol 158:259-265. https://doi.org/10.1016/j.seppur.2015.12.028

Duong HC, Duke M, Gray S, Cooper P, Nghiem LD (2016) Membrane scaling and prevention techniques during seawater desalination by air gap membrane distillation. Desalination 397:92-100. https:// doi.org/10.1016/j.desal.2016.06.025

El Amali A, Bouguecha S, Maalej M (2004) Experimental study of air gap and direct contact membrane distillation configurations: Application to geothermal and seawater desalination. Desalination 168:357. https://doi.org/10.1016/j.desal.2004.07.020

El-Ghandour M, Elhenawy Y, Farag A, Shatat M, Moustafa GH, Experimental investigation of a system of two air-gap-membranedistillation modules with heat recovery, (N.D.)

Elhenawy Y, Elminshawy NAS, Bassyouni M, AlhathalAlanezi A, Drioli E (2019) Experimental and theoretical investigation of a new air gap membrane distillation module with a corrugated feed channel. J Memb Sci. https://doi.org/10.1016/j.memsci.2019.117461

Elhenawy Y, Elminshawy NAS, Bassyouni M, Alhathal Alanezi A, Drioli E (2020) Experimental and theoretical investigation of a new air gap membrane distillation module with a corrugated feed channel. J Memb Sci 594:117461. https://doi.org/10.1016/j.memsci.2019.117461

Francis L, Ghaffour N, Alsaadi AA, Amy GL (2013) Material gap membrane distillation: a new design for water vapor flux enhancement. J Memb Sci 448:240-247. https://doi.org/10.1016/j.memsci. 2013.08.013

Gao L, Zhang J, Gray S, Li J-D (2019) Influence of PGMD module design on the water productivity and energy efficiency in desalination. Desalination 452:29-39. https://doi.org/10.1016/j.desal. 2018.10.005

Garciá-Payo MC, Izquierdo-Gil MA, Fernández-Pineda C (2000) Air gap membrane distillation of aqueous alcohol solutions. J Memb Sci 169:61-80. https://doi.org/10.1016/S0376-7388(99)00326-9

Geng H, He Q, Wu H, Li P, Zhang C, Chang H (2014) Experimental study of hollow fiber AGMD modules with energy recovery for high saline water desalination. Desalination 344:55-63. https:// doi.org/10.1016/j.desal.2014.03.016

Geng H, Lin L, Li P, Zhang C, Chang H (2016) Study on the heat and mass transfer in AGMD module with latent heat recovery. Desalin Water Treat 57:15276-15284. https://doi.org/10.1080/19443994. 2015.1074122

Goh PS, Matsuura T, Ismail AF, Hilal N (2016) Recent trends in membranes and membrane processes for desalination. Desalination 391:43-60. https://doi.org/10.1016/j.desal.2015.12.016

Guijt CM, Meindersma GW, Reith T, De Haan AB (2005) Air gap membrane distillation: 2 Model validation and hollow fibre module performance analysis. Sep Purif Technol 43:245-255. https:// doi.org/10.1016/j.seppur.2004.09.016

Guijt CM, Meindersma GW, Reith T, De Haan AB (2005) Air gap membrane distillation: 1 modelling and mass transport properties for hollow fibre membranes. Sep Purif Technol 43:233-244. https://doi.org/10.1016/j.seppur.2004.09.015

Hanemaaijer JH, van Medevoort J, Jansen AE, Dotremont C, van Sonsbeek E, Yuan T, De Ryck L (2006) Memstill membrane distillation: a future desalination technology. Desalination 199:175-176. https://doi.org/10.1016/j.desal.2006.03.163

Im B-G, Lee J-G, Kim Y-D, Kim W-S (2018) Theoretical modeling and simulation of AGMD and LGMD desalination processes using a composite membrane. J Memb Sci 565:14-24. https://doi.org/10. 1016/j.memsci.2018.08.006

Im BG, Lee JG, Kim YD, Kim WS (2018) Theoretical modeling and simulation of AGMD and LGMD desalination processes using a composite membrane. J Memb Sci. https://doi.org/10.1016/j. memsci.2018.08.006

Incropera FP (2006) Fundamentals of heat and mass transfer. Wiley, Hoboken

Izquierdo-Gil MA, García-Payo MC, Fernández-Pineda C (1999) Air gap membrane distillation of sucrose aqueous solutions. J Memb Sci 155:291-307. https://doi.org/10.1016/S0376-7388(98) 00323-8

Kerdi S, Qamar A, Alpatova A, Vrouwenvelder JS, Ghaffour N (2020) Membrane filtration performance enhancement and biofouling mitigation using symmetric spacers with helical filaments. Desalination. https://doi.org/10.1016/j.desal.2020.114454

Khalifa AE, Lawal DU (2015) Performance and Optimization of Air Gap Membrane Distillation System for Water Desalination. Arab J Sci Eng 40:3627-3639. https://doi.org/10.1007/ s13369-015-1772-0

Khalifa AE, Lawal DU (2016) Application of response surface and Taguchi optimization techniques to air gap membrane distillation for water desalination: a comparative study. Desalin Water Treat 57:28513-28530. https://doi.org/10.1080/19443994.2016. 1189850

Khayet M, Cojocaru C (2012) Air gap membrane distillation: Desalination, modeling and optimization. Desalination 287:138-145. https://doi.org/10.1016/j.desal.2011.09.017

Khayet M, Matsuura T (2011) Air gap membrane. Distillation. https:// doi.org/10.1016/b978-0-444-53126-1.10013-2

Khayet M, Matsuura T (2011b) Air gap membrane. Distillation. https:// doi.org/10.1016/b978-0-444-53126-1.10013-2

Khayet M, Matsuura T (2011) Introduction to membrane distillation. Membr Distill. https://doi.org/10.1016/b978-0-444-53126-1. 10001-6

Khayet M, Matsuura T (2011) Economics energy analysis and costs evaluation in MD. Membr Distill. https://doi.org/10.1016/b9780-444-53126-1.10015-6

Kumar DS (2008) Heat and mass transfer: SI Units, S K Kataria. https://books.google.co.in/books?id=-2fqnQEACAAJ

Lee J, Alsaadi AS, Ghaffour N (2019) Multi-stage air gap membrane distillation reversal for hot impaired quality water treatment: concept and simulation study. Desalination 450:1-11. https://doi.org/ 10.1016/J.DESAL.2018.10.020

Liu Z, Gao Q, Lu X, Zhao L, Wu S, Ma Z, Zhang H (2016) Study on the performance of double-pipe air gap membrane distillation module. Desalination 396:48-56. https://doi.org/10.1016/j.desal. 2016.04.025

Matheswaran M, Kwon TO, Kim JW, Moon IS (2007) Factors affecting flux and water separation performance in air gap membrane distillation. J Ind Eng Chem 13:965-970

Moejes SN, van Wonderen GJ, Bitter JH, van Boxtel AJB (2020) Assessment of air gap membrane distillation for milk concentration. J Memb Sci 594:117403. https://doi.org/10.1016/j.memsci. 2019.117403

Ruiz-Aguirre A, Andrés-Mañas JA, Fernández-Sevilla JM, Zaragoza G (2017) Modeling and optimization of a commercial permeate gap spiral wound membrane distillation module for seawater desalination. Desalination 419:160-168. https://doi.org/10.1016/j. desal.2017.06.019

Schwantes R, Seger J, Bauer L, Winter D, Hogen T, Koschikowski J, Geißen SU (2019) Characterization and assessment of a novel plate and frame md module for single pass wastewater concentration-feed gap air gap membrane distillation. Membranes. https:// doi.org/10.3390/membranes 9090118 
Shahu VT, Thombre SB (2019a) Air gap membrane distillation: a review. J Renew Sustain Energy 11:45901. https://doi.org/10. $1063 / 1.5063766$

Shahu VT, Thombre SB (2019b) Analysis and optimization of a new cylindrical air gap membrane distillation system. Water Supply. https://doi.org/10.2166/ws.2019.164

Shahu VT, Thombre SB (2021) Experimental analysis of a novel helical air gap membrane distillation system. Water Supply. https:// doi.org/10.2166/ws.2021.002

Singh D, Sirkar KK (2012) Desalination by air gap membrane distillation using a two hollow-fiber-set membrane module. J Memb Sci 421-422:172-179. https://doi.org/10.1016/j.memsci.2012.07.007

Suárez F, Ruskowitz JA, Tyler SW, Childress AE (2015) Renewable water: direct contact membrane distillation coupled with solar ponds. Appl Energy 158:532-539. https://doi.org/10.1016/j.apene rgy.2015.08.110

Summers EK, Lienhard JH (2013) Experimental study of thermal performance in air gap membrane distillation systems, including the direct solar heating of membranes. Desalination 330:100-111. https://doi.org/10.1016/j.desal.2013.09.023

Summers EK, Arafat HA, Lienhard JH (2012) Energy efficiency comparison of single-stage membrane distillation (MD) desalination cycles in different configurations. Desalination 290:54-66. https:// doi.org/10.1016/J.DESAL.2012.01.004

Swaminathan J, Chung HW, Warsinger DM, AlMarzooqi FA, Arafat HA, Lienhard JHV (2016) Energy efficiency of permeate gap and novel conductive gap membrane distillation. J Memb Sci 502:171-178. https://doi.org/10.1016/j.memsci.2015.12.017

Swaminathan J, Chung HW, Warsinger DM, AlMarzooqi FA, Arafat HA, Lienhard JH (2016b) Energy efficiency of permeate gap and novel conductive gap membrane distillation. J Memb Sci 502:171-178. https://doi.org/10.1016/j.memsci.2015.12.017

Swaminathan J, Chung HW, Warsinger DM, Lienhard JHV (2018) Energy efficiency of membrane distillation up to high salinity: evaluating critical system size and optimal membrane thickness. Appl Energy 211:715-734. https://doi.org/10.1016/J.APENE RGY.2017.11.043

Szczerbińska J, Kujawski W, Arszyńska JM, Kujawa J (2017) Assessment of air-gap membrane distillation with hydrophobic porous membranes utilized for damaged paintings humidification. J Memb Sci 538:1-8. https://doi.org/10.1016/j.memsci.2017.05.048

Wang K, Abdalla AA, Khaleel MA, Hilal N, Khraisheh MK (2017) Mechanical properties of water desalination and wastewater treatment membranes. Desalination 401:190-205. https://doi.org/10. 1016/j.desal.2016.06.032

Warsinger DEM, Swaminathan J, Maswadeh LA, Lienhard JH (2015) Superhydrophobic condenser surfaces for air gap membrane distillation. J Memb Sci 492:578-587. https://doi.org/10.1016/j. memsci.2015.05.067

Woo YC, Tijing LD, Park MJ, Yao M, Choi J-S, Lee S, Kim S-H, An K-J, Shon HK (2017) Electrospun dual-layer nonwoven membrane for desalination by air gap membrane distillation. Desalination 403:187-198. https://doi.org/10.1016/j.desal.2015.09.009

Xie M, Shon HK, Gray SR, Elimelech M (2016) Membrane-based processes for wastewater nutrient recovery: technology, challenges, and future direction. Water Res 89:210-221. https://doi.org/10. 1016/j.watres.2015.11.045

Zhang Y, Peng Y, Ji S, Li Z, Chen P (2015) Review of thermal efficiency and heat recycling in membrane distillation processes. Desalination 367:223-239. https://doi.org/10.1016/j.desal.2015. 04.013

Zuo G, Wang R, Field R, Fane AG (2011) Energy efficiency evaluation and economic analyses of direct contact membrane distillation system using Aspen Plus. Desalination 283:237-244. https://doi. org/10.1016/j.desal.2011.04.048

Publisher's note Springer Nature remains neutral with regard to jurisdictional claims in published maps and institutional affiliations. 